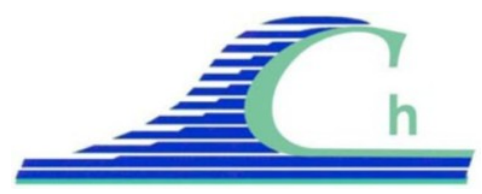

XII ${ }^{\text {èmes }}$ Journées Nationales Génie Côtier - Génie Civil

Cherbourg, 12-14 juin 2012

DOI:10.5150/jngcgc.2012.021-B C Editions Paralia CFL

disponible en ligne - http://www.paralia.fr-available online

\title{
Dynamique sédimentaire intertidale en baie du Mont-Saint- Michel entre évolution naturelle et aménagements
}

\author{
Chantal BONNOT-COURTOIS ${ }^{1}$ \\ en hommage à Alain L'HOMER †
}

\author{
1. CNRS, UMR 8586 PRODIG. \\ chantalbonnot0577@orange.fr
}

\section{Résumé :}

L'amplitude exceptionnelle des marées (marnage de $14 \mathrm{~m}$ en vives-eaux) et l'immensité de l'estran $\left(250 \mathrm{~km}^{2}\right)$ font de la baie du Mont-Saint-Michel un des rares exemples dans le Monde d'un système hydro-sédimentaire évoluant en régime mégatidal. Cet environnement est remarquable par la diversité et la richesse des faciès biosédimentaires du littoral (vase calcaire, Hermelles). L'objectif de cet article est $\mathrm{d}$ 'analyser les processus érosion/sédimentation qui règlent la dynamique sédimentaire et l'évolution récente des environnements sédimentaires. Le fond de baie occidental comprend des dépôts tidaux sablo-vaseux où l'amplitude interannuelle des remaniements sédimentaires superficiels est faible $(<10 \mathrm{~cm})$ et liée à la nature du substrat et à l'orientation des vents. A cette dynamique tidale se surimpose une dynamique de houle qui, en affouillant les grèves, met en mouvement des sables bioclastiques grossiers qui migrent sur l'estran à des vitesses de plusieurs dizaines de $\mathrm{m} / \mathrm{an}$ et s'accumulent sur le haut estran pour former une barrière littorale discontinue et relativement stable de grands bancs coquilliers. La partie orientale de la baie correspond à la zone estuarienne où la morpho-dynamique de l'estran sableux est pilotée par la divagation des chenaux. L'étude de l'interaction végétation/sédimentation aux abords du Mont-Saint-Michel montre des taux d'accrétion sédimentaire variant de 0,2 à $10 \mathrm{~cm} / \mathrm{an}$, dépendant du contexte morpho-dynamique du front des schorres. Le volume des apports sédimentaires par la marée permet le dépôt rythmé des tangues suivi par la progression régulière des herbus d'environ 17 ha/an entre La Chapelle Sainte-Anne et la pointe de Roche Torin. Le remplissage de la baie s'effectue depuis des millénaires au rythme des oscillations du niveau marin, aboutissant au comblement progressif du marais de Dol et à une progradation de la ligne de rivage. Au-delà de cette évolution naturelle, les activités humaines qui se sont développées dans la baie, tant sur l'estran occidental (pêcheries fixes, conchyliculture) qu'à l'Est côté estuarien (poldérisation, construction de digues et de barrage) ont modifié les paysages dont l'évolution historique a pu être reconstituée à partir de documents anciens.

\section{Mots-clés :}

Processus hydro-sédimentaires intertidaux - Baie du Mont-Saint-Michel - Régime mégatidal - Dynamique sédimentaire - Aménagements - Evolution récente 


\section{Avant-Propos}

Cet article est la synthèse des études hydro-sédimentaires réalisées en baie du MontSaint-Michel au cours des années 2000 au sein du Laboratoire de Géomorphologie et Environnement littoral EPHE de l'UMR 8586 PRODIG du CNRS. Elles ont été financées dans le cadre de plusieurs programmes de recherche en particulier le volet "Etudes en Environnement" du Projet de Rétablissement du caractère maritime du Mont-Saint-Michel (Mission Mont-Saint-Michel de la DDE Manche et Syndicat Mixte pour le Rétablissement du Caractère Maritime du Mont) et le chantier "Capacité trophique de la baie du Mont-Saint-Michel" du Programme National Environnement Côtier (PNEC du CNRS).

Ce travail n'aurait pu être mené à bien sans la collaboration de nombreux collègues que nous tenons à remercier ici : A. Baltzer, B. Tessier (CNRS / Univ. Caen), M. Le Vot et H. Gloria (EPHE, Dinard), J.E. Levasseur (Univ. Rennes 1), B. Caline, (TOTAL, Pau), R. Desguée (Syndicat Mixte Baie du Mont-Saint-Michel) J.Y Cocaign (Ecomusée de Vains, CG50), C. Billard (DRAC-SRA, Basse Normandie), P. Le Mao, C. Rollet (Ifremer, Dinard), C. Retière, J. Fournier (MNHN/CNRS, Dinard), C. Augris, Ph. Bassoullet, J.P. Mazé, P. Le Hir, J. Populus, (Ifremer, Brest), ainsi que tous les étudiants et techniciens qui ont participé à ces recherches.

Enfin une pensée toute particulière va vers Alain L'HOMER qui nous a quittés en 2011 et que je remercie sincèrement pour m'avoir fait partager sa connaissance encyclopédique des environnements sédimentaires de la baie et de ses marais dont il a su reconstituer l'évolution des paysages présentée dans cet article.

\section{Introduction}

Abritant de nombreux habitats naturels de grande importance, la baie du Mont-SaintMichel a été choisie pour intégrer le réseau européen des sites Natura 2000 et le Mont est inscrit au patrimoine mondial de l'humanité, ce qui implique une analyse précise de l'évolution naturelle de ces milieux très convoités et soumis à des activités anthropiques variées. Deux programmes récents ont permis d'étudier plus finement la dynamique sédimentaire intertidale actuelle.

Dans le cadre du thème hydro-sédimentaire du chantier "Capacité trophique de la baie du Mont-Saint-Michel" du Programme national environnement côtier (PNEC), une nouvelle cartographie morpho-sédimentaire de la baie a été élaborée et a été couplée à un levé LIDAR sur l'ensemble de la baie, permettant de mettre en évidence les niveaux de submersion de l'estran et de les corréler avec la dynamique sédimentaire actuelle. Des mesures in situ des processus érosion/sédimentation ont par ailleurs été réalisées afin de suivre l'amplitude des remaniements et les déplacements des nappes de vases superficielles. Par ailleurs, la comparaison d'une chronique de photos aériennes depuis 1952 géoréférencées par rapport à l'ortholittorale 2000 a conduit à une quantification de 


\section{XII ${ }^{\text {èmes }}$ Journées Nationales Génie Côtier - Génie Civil \\ Cherbourg, 12-14 juin 2012}

la dynamique des bancs coquilliers qui forment la barrière littorale du haut estran occidental.

Dans le cadre du Projet de Rétablissement du caractère maritime du Mont-Saint-Michel, les études en environnement consacrées à la dynamique des herbus ont conduit à analyser l'interaction végétation/sédimentation dans les schorres aux abords du MontSaint-Michel. Les mesures de l'accrétion sédimentaire et des apports en matières en suspension au front des schorres montrent l'influence des conditions morphodynamiques de la haute slikke sur l'évolution des schorres. La même chronique de photos aériennes que pour les bancs coquilliers a été utilisée pour quantifier précisément la progression ou le recul des schorres aux abords du Mont-Saint-Michel.

Enfin, l'évolution des paysages de la baie a pu être reconstituée à partir de documents anciens et a permis de retracer l'impact des aménagements successifs réalisés sur l'ensemble de l'estran au fil des siècles.

\section{Présentation générale. Cadre physique}

Depuis longtemps, la baie du Mont-Saint-Michel a fait l'objet d'innombrables travaux scientifiques tant en sédimentologie qu'en biologie ou en archéologie et une liste non exhaustive des principaux travaux de référence et de synthèse est fournie en bibliographie.

Entre la pointe du Grouin à l'ouest et la pointe de Champeaux à l'est, l'estran de la baie du Mont-Saint-Michel se découvre sur une surface de $250 \mathrm{~km}^{2}$ et se subdivise en deux grands ensembles morpho-sédimentaires. Le domaine occidental, de Cancale à Cherrueix, correspond à un fond de baie abrité, découvrant sur une largeur de $5 \mathrm{~km}$ et comprenant des vases homogènes entaillées par les deux exutoires des canaux de drainage du marais de Dol. La partie orientale correspond à un vaste domaine estuarien au débouché de trois fleuves côtiers à faible débit : la Sée, la Sélune et le Couesnon. Cet estran oriental, large de $10 \mathrm{~km}$ et parcouru par un réseau dense de chenaux de marée, est soumis à un régime hydrodynamique intense qui remobilise les fonds sableux. À la jonction entre la baie occidentale et la zone estuarienne orientale se trouve une bioconstruction récifale à Annélides (Sabellaria alveolata) qui s'est développée au niveau du bas estran pour former le banc des Hermelles. (LARSONNEUR \& coll., 1989 ; L'HOMER et al., 1999 ; BONNOT-COURTOIS et al., 2002).

\subsection{Contexte hydrodynamique}

Exceptionnellement fortes en baie du Mont-Saint-Michel (marnage de $14 \mathrm{~m}$ en période de vive-eau), les marées jouent un rôle déterminant dans la répartition des sédiments sur les petits fonds immergés et sur l'estran. Deux régimes de courants de marée coexistent dans la baie (figure 1) :

- au large de la pointe du Grouin et au nord-est dans l'axe médian de la baie, les courants sont alternatifs, le flot dirigé vers le sud-est est plus intense que le jusant 
portant au nord-ouest. À l'entrée de la baie, les vitesses des courants peuvent dépasser $1 \mathrm{~m} / \mathrm{s}$ puis elles diminuent autour de $0,6 \mathrm{~m} / \mathrm{s}$ sur l'estran, excepté dans les chenaux estuariens où elles dépassent $2 \mathrm{~m} / \mathrm{s}$.

- au sud-ouest, les courants ont un caractère giratoire avec toujours une prédominance du flot sur le jusant mais des vitesses très atténuées $(0,3 \mathrm{~m} / \mathrm{s})$ en baie de Cancale.

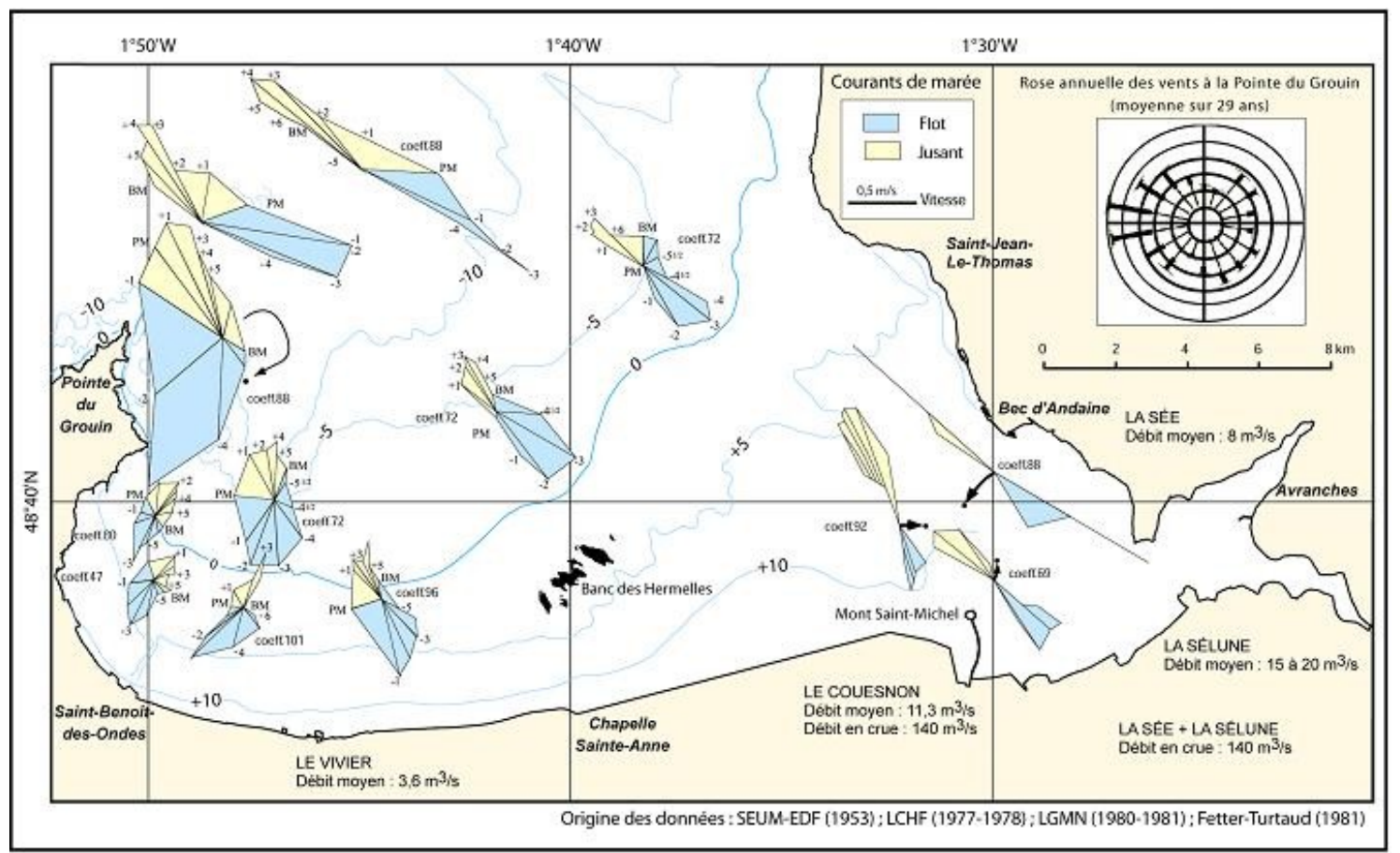

Figure 1. Roses des courants de marée et des vents en baie du Mont-Saint-Michel.

Les vents dominants sont de secteur ouest à nord-ouest et les houles les plus fréquentes sont également de secteur ouest-nord-ouest (figure 2).

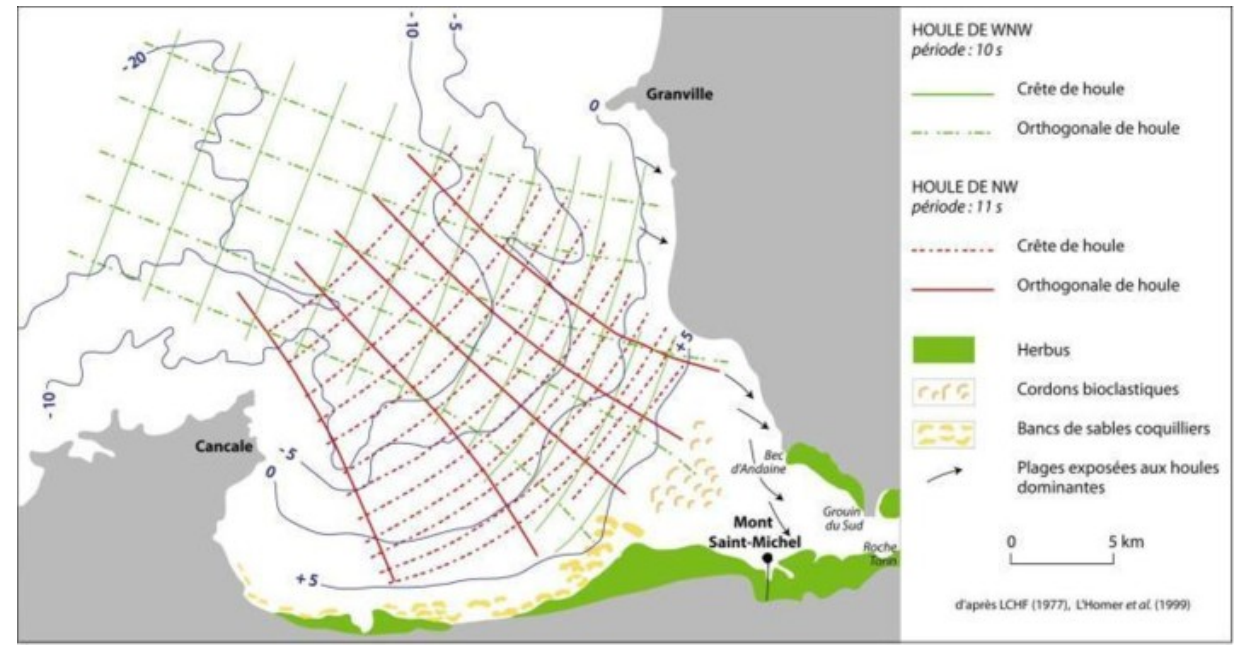

Figure 2. Plan de vagues de secteur Ouest en baie du Mont-Saint-Michel. 


\section{XII ${ }^{\text {èmes }}$ Journées Nationales Génie Côtier - Génie Civil \\ Cherbourg, 12-14 juin 2012}

À l'entrée de la baie, les houles sont diffractées autour de la pointe du Grouin, de sorte que la baie de Cancale est totalement protégée de l'agitation. En progressant dans l'axe médian de la baie, les houles s'amortissent presque totalement par frottement sur l'estran très plat et particulièrement large dans la zone estuarienne. L'effet des houles se fait sentir essentiellement sur le littoral normand, entre Saint-Jean-le-Thomas et le Bec d'Andaine (TESSIER et al., 2006), et dans une moindre mesure sur l'estran occidental au centre de la baie où les houles diffractées, de secteur nord, sont à l'origine d'accumulations coquillières sur le haut estran entre Saint-Benoît-des-Ondes et La Chapelle Sainte-Anne (MIGNIOT, 1998 ; L'HOMER et al., 1999).

\subsection{Cartographie morpho-sédimentaire (figure 3)}

Dans le cadre du thème hydro-sédimentaire du chantier "Capacité trophique de la baie du Mont-Saint-Michel" du Programme National Environnement Côtier (PNEC, 2007), une actualisation de la couverture sédimentaire de la baie a été effectuée à partir de l'analyse de 400 prélèvements sédimentaires et biologiques répartis régulièrement (1 point par $\mathrm{km}^{2}$ ) en zone intertidale et subtidale. La cartographie intertidale a été élaborée par couplage des résultats de l'analyse granulométrique laser permettant de caractériser les faciès sédimentaires, et de l'interprétation des clichés bruts de l'ortho-littorale IGN (2002) ayant servi de support pour déterminer les limites de faciès (BONNOTCOURTOIS et al. 2007)

Le domaine marin à l'entrée de la baie comprend des nappes de cailloutis et de graviers sur un substratum rocheux qui affleure largement au nord-est de la pointe du Grouin. Ces sédiments très grossiers laissent place à des graviers sableux qui forment des bancs à proximité des caps. Au Nord-Ouest de la baie, ils se mélangent à un abondant stock de coquilles, en particulier de crépidule, espèce invasive qui recouvre largement la surface des fonds subtidaux jusqu'aux secteurs envasés des parcs ostréicoles de Cancale. Des couloirs, constitués de graviers coquilliers et de sables grossiers, localement modelés en mégarides, recoupent le prisme sableux entre le banc des Hermelles et la pointe de Champeaux. Au centre de la baie, le banc situé au nord du récif des Hermelles de Sainte-Anne coïncide avec l'ancien lit du Couesnon. Au nord-est, le couloir ancré sur la pointe de Champeaux comprend des sables grossiers mieux classés, témoins d'une dynamique sédimentaire active.

La répartition des sédiments subtidaux et intertidaux de la baie du Mont-Saint-Michel reflète l'action prépondérante des courants de marée dont les vitesses diminuent progressivement du large vers le trait de côte. Deux gradients sédimentaires majeurs apparaissent en relation avec l'atténuation de l'hydrodynamique :

- du large vers la côte, les nappes de sables grossiers et cailloutis, orientées nord-ouest

- sud-est dans l'axe de la baie, passent progressivement aux sables moyens et fins puis aux faciès vaseux dans les parties les plus hautes de l'estran. 
- d'est en ouest, les sables fins de la zone estuarienne, mis en place sous l'action de courants de marée de type alternatif, passent à des faciès sablo-vaseux dans la partie centrale de la baie. Des faciès encore plus fins de vases pures occupent la baie de Cancale, soumise à des courants giratoires et totalement protégée des houles de nordouest, diffractées par la pointe du Grouin.

Nature des sédiments superficiels

Roche toujours immergée (a)
Cailloutis et blocs
Graviers et cailloutis
Graviers et sables grossiers
Sables grossiers, graviers, calloux
Sables moyens et grossiers à graviers
Sables grossiers
Sables moyens et grossiers bioclastques
Sables moyens
Sables moyens des chenaux
Sables fins

Morphologie \& figures sédimentaires

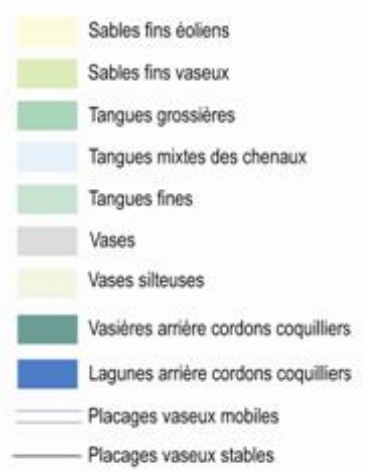

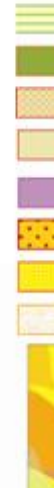
Anciens bancs coquiliers végétalisés $\quad 2,3 \%$, Rubans sableux Bancs coquiliers de haute silike Bancs coquiliers d'estran

Bancs sableux liés aux Hermelles Bancs de sables grossiers Bancs sableux de la zone estuarienne Levées de rives

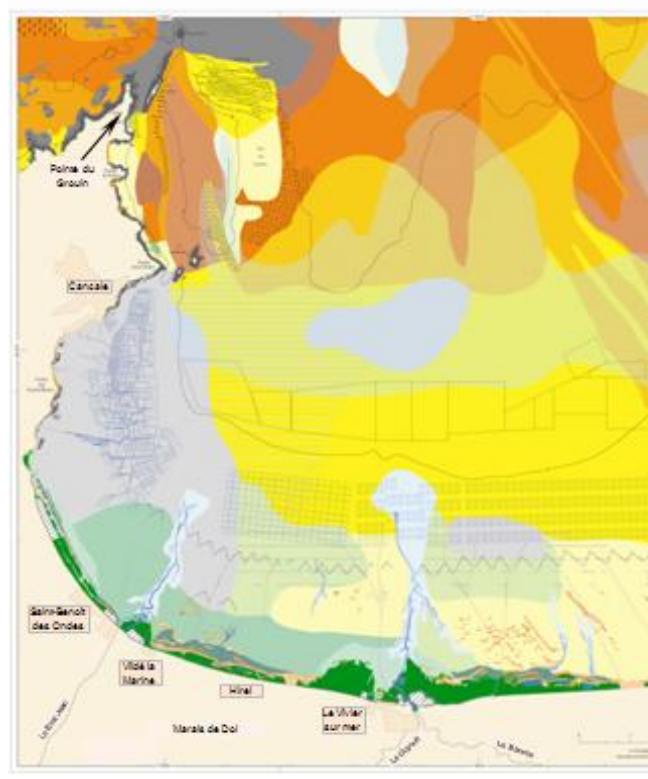

- Mégarides (longueur d'onde $<5 \mathrm{~m}$ ) _ Mégarides (longueur donde $>5 \mathrm{~m}$ ) Crette de dune hydraulique

Crête de banc

Rides de bas estran -20 - Isobathe en $m$ (SHOM) Biocénoses remarquables

Figure 3. Répartition des sédiments superficiels en baie du Mont-Saint-Michel (d'après BONNOT-COURTOIS et al. 2009).

Les faciès sédimentaires de la partie occidentale évoluent d'un estran plat constitué de vase pure à Cancale à un environnement sablo-vaseux en face de Vildé-Hirel, puis à un estran sableux formé de sables fins et moyens devant Cherrueix, à l'est du chenal du Vivier. Le bas estran de ce fond de baie occidentale est marqué par le grand développement des installations conchylicoles : ostréiculture en baie de Cancale et mytiliculture entre Vildé-la-Marine et au-delà de Cherrueix jusqu'au large du récif des 


\section{XII ${ }^{\text {èmes }}$ Journées Nationales Génie Côtier - Génie Civil \\ Cherbourg, 12-14 juin 2012}

Hermelles et du débouché de la zone estuarienne. Sont également présentes de nombreuses pêcheries anciennes, installées au niveau du moyen estran selon un alignement presque continu entre Saint-Benoît-des-Ondes et Cherrueix.

\subsection{Topographie et submersion de l'estran . Données LIDAR}

Dans le cadre du PNEC, une bathymétrie des petits fonds subtidaux et un levé LIDAR topographique sur l'estran, réalisés en 2002, ont permis d'établir un MNT de l'ensemble de la baie (figure 4). La couverture LIDAR avec une résolution au sol de $2 \mathrm{~m}$ et une précision altimétrique inférieure à $15 \mathrm{~cm}$ offre des perspectives extrêmement intéressantes pour détailler la topographie de la zone intertidale et la morphologie des unités sédimentaires.

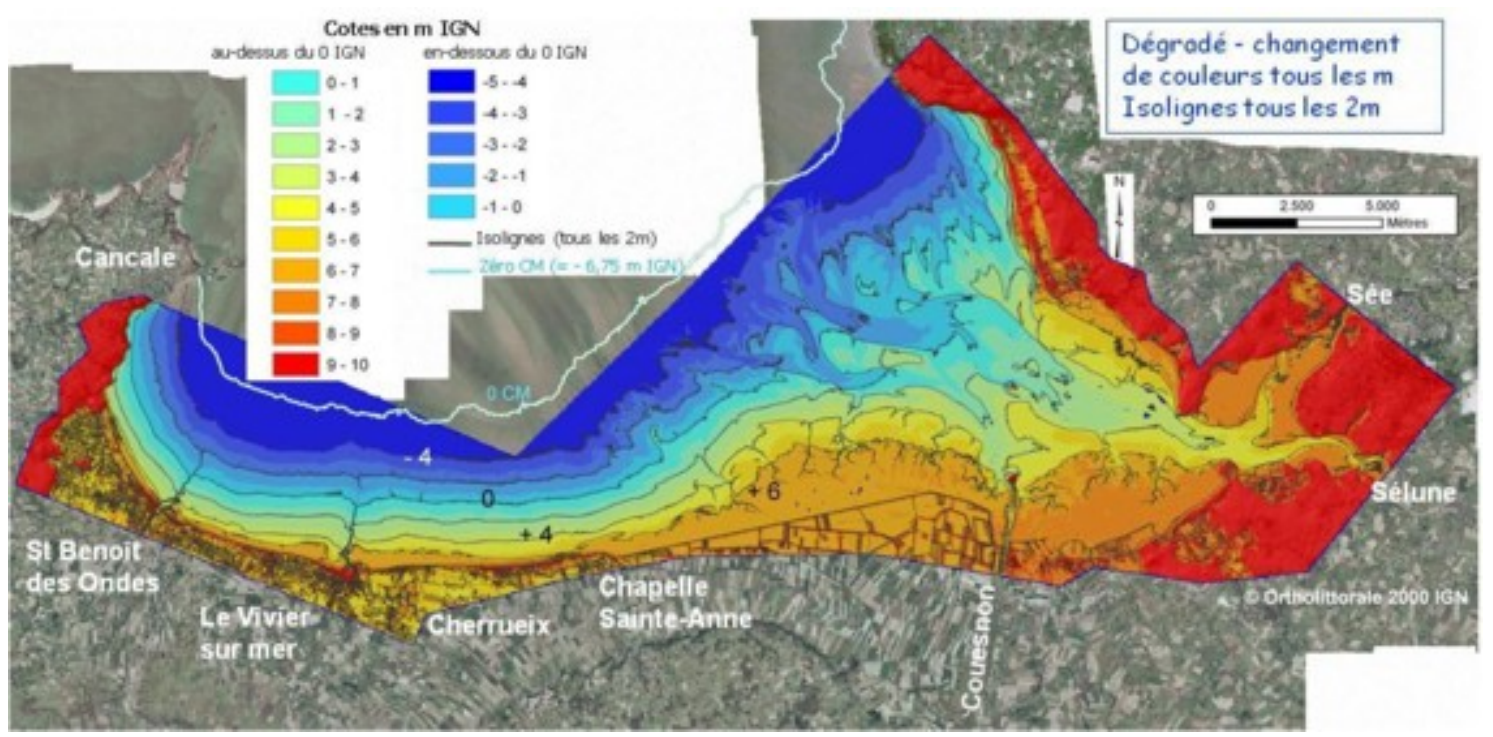

Figure 4. MNT de la zone intertidale extrait du LIDAR 2002.

La partie occidentale de l'estran, entre Cancale et La Chapelle Sainte-Anne, présente une topographie régulière en pente douce, seulement interrompue par les deux exutoires des canaux de drainage du marais de Dol à Saint-Benoît-des-Ondes et au Vivier-surmer. La largeur de l'estran occidental est d'environ $5 \mathrm{~km}$ et les pentes varient de $0,55 \%$ à Vildé-Hirel à $0,38 \%$ à Cherrueix pour tomber à $0,31 \%$ à La Chapelle Sainte-Anne. Elles sont encore plus faibles dans la zone estuarienne où la largeur de l'estran dépasse $10 \mathrm{~km}$ avec des pentes de l'ordre de $0,15 \%$. Le niveau moyen de marée (0 IGN) est situé à $6,74 \mathrm{~m}$ au-dessus du zéro hydrographique $(0 \mathrm{CM})$ et la cote $6 \mathrm{~m}$ IGN correspond à la limite du tapis végétal continu sur le haut estran oriental.

Le couplage de cette topographie fine couvrant l'ensemble de la zone intertidale avec les niveaux de marée pour tous coefficients classés de 10 en 10 permet de mettre en évidence les niveaux de submersion de l'estran. Les niveaux de Pleine Mer et Basse Mer ont été calculés en faisant la moyenne sur 50 ans (période 1950 - 2000) afin de 
lisser les effets des variations interannuelles (cycles à 4 ans et Saros à 18 ans) (figure 5) (BONNOT-COURTOIS et al. 2009 ; WEILL, 2010).

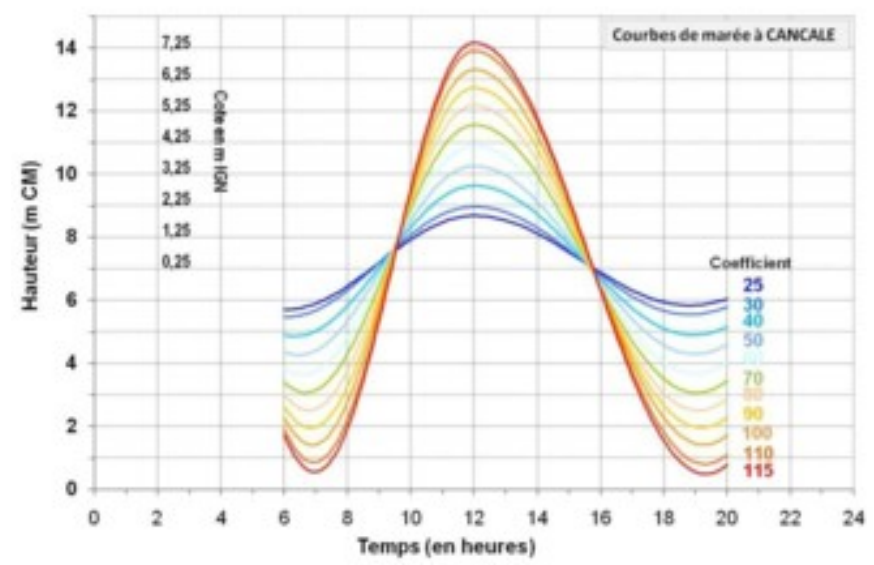

Figure 5. Courbes de marée moyennes par coefficient à Cancale.

Les niveaux moyens théoriques de $\mathrm{PM}$ et $\mathrm{BM}$ ainsi obtenus sont reportés sur la topographie intertidale et permettent d'obtenir le balayage de la marée sur l'estran pour tout type de marée de morte eau ou de vive eau (figure 6). La surface des zones découvrantes en marée de vives eaux est environ deux fois plus importante que lors des mortes eaux. Elle est également beaucoup plus large dans la zone estuarienne (environ $10 \mathrm{~km}$ en vive eau) qu'au niveau de la baie de Cancale (5 $\mathrm{km}$ en vive eau).

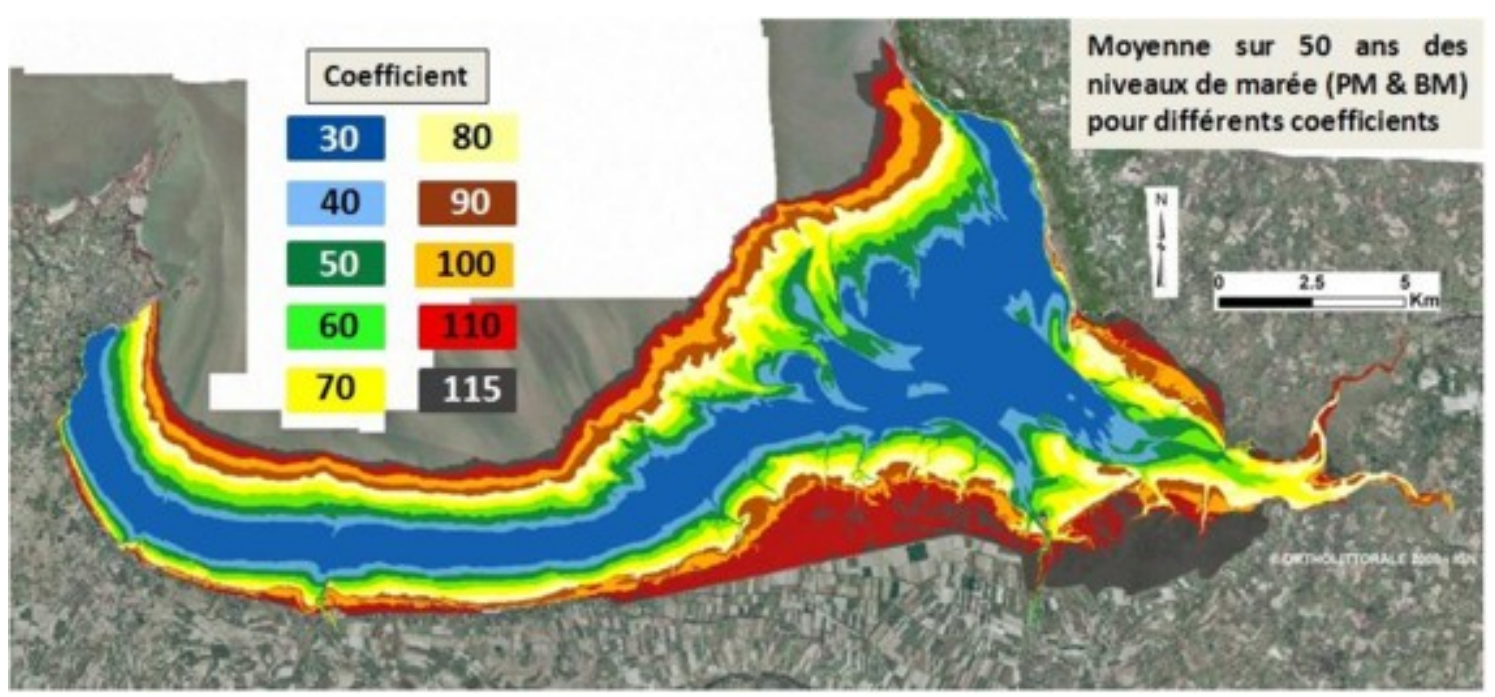

Figure 6. Balayage de la zone intertidale par les marées des différents coefficients classés de 10 en 10. Moyennes des niveaux de Pleine Mer et Basse Mer établies sur 50 ans (1950 à 2000). 


\section{XII ${ }^{\text {èmes }}$ Journées Nationales Génie Côtier - Génie Civil \\ Cherbourg, 12-14 juin 2012}

\section{Processus et dynamique sédimentaire du haut estran occidental}

\subsection{Erosion - sédimentation sur l'estran occidental}

Le thème hydro-sédimentaire du chantier PNEC avait pour objectif de caractériser les transports dissous et particulaires et d'analyser les rythmes et l'ampleur des processus érosion - sédimentation qui s'opèrent sur ces très vastes replats de marée où sont implantées les installations conchylicoles. Le suivi des variations du niveau du sédiment a été réalisé à 3 échelles de temps, le long de trois radiales transversales longues de plusieurs $\mathrm{km}$ et représentatives des différents environnements sédimentaires, vaseux à Cancale, sablo-vaseux à Vildé-Hirel et sableux à Cherrueix. Les évolutions de la couverture sédimentaire superficielle et les phases d'érosion et de dépôt mises en évidence dépendent de la localisation sur l'estran et des conditions marégraphiques et météorologiques (BONNOT-COURTOIS et al., 2006, 2007).

L'amplitude des remaniements est relativement faible $(<5 \mathrm{~cm})$ et variable d'Ouest en Est: importants à Cancale et à Vildé-Hirel, ils sont beaucoup plus faibles à Cherrueix. A certaines périodes de l'année, en particulier hivernales, l'ensemble de l'estran connait des phases d'érosion de plusieurs $\mathrm{cm}$, rapidement suivies de phases de sédimentation de même amplitude. Un équilibre spatial semble s'établir entre les deux radiales les plus occidentales : une phase d'érosion des vases superficielles à Hirel coïncidant avec une phase de sédimentation à Cancale. Ainsi, l'action érosive des vents de secteur Ouest à Nord sur la totalité de l'estran de Cancale peut être mise en relation avec le dépôt de sédiments fins par ces mêmes vents sur le secteur amont des pêcheries de Vildé-Hirel. De même, les vents de Sud-Est érodent le moyen estran de Vildé-Hirel et engraissent le mud flat de Cancale.

\subsection{Dynamique des bancs coquilliers}

Le haut estran occidental de la baie du Mont-Saint-Michel, entre Saint-Benoît des Ondes et La Chapelle Sainte-Anne, est caractérisé par la présence de nombreux et volumineux bancs coquilliers, alignés parallèlement au trait de côte. Ces accumulations bioclastiques, liées à l'action des houles, présentent différents types morphologiques selon leurs caractéristiques morpho-sédimentaires : granulométrie, contenu bioclastique, amplitude, position sur l'estran... Les bancs sableux d'estran situés dans la partie médiane de l'estran sont peu épais $(30 \mathrm{~cm})$ mais de grande extension spatiale. Au niveau du haut estran, les bancs de haute slikke, enrichis en coquilles entières sont très épais $(2 \mathrm{~m})$ et présentent une morphologie dissymétrique à pente douce vers la mer et raide vers le rivage, avec des terminaisons en crochons tournés vers la côte. Situés en bordure du schorre, ils isolent en arrière d'eux une dépression lagunaire où se déposent des vases fines, particulièrement sur les secteurs de Vildé-Hirel et de Cherrueix (figure 7). Les bancs de schorre, d'épaisseur variable et de faible extension latérale sont formés 
majoritairement de coquilles entières et sont incorporés à l'intérieur du schorre où ils sont progressivement colonisés par la végétation dunaire.

A Vildé-Hirel, les bancs d'estran sont bien individualisés sur un mixed-flat sablovaseux et ceux de haute slikke, de grande extension longitudinale, forment une barrière littorale presque continue. A Cherrueix, de très nombreux bancs d'estran de petite taille s'étagent sur un estran de sables fins et les bancs coquilliers de haute slikke se répartissent en plusieurs alignements discontinus. A la Chapelle Sainte-Anne, les bancs d'estran sont rares sur le sand-flat de sables fins et moyens et quelques bancs de haute slikke de grande extension se rencontrent dans l'Ouest du secteur. Ils font place vers l'Est aux grands bancs litho-bioclastiques associés aux récifs d'Hermelles.

Le levé LIDAR montre que la cote altimétrique de ces bancs est élevée (7,5 m IGN), et qu'ils ne sont recouverts qu'exceptionnellement par les pleines mers de grande vive eau (figure 7). Il existe des variations longitudinales de submersion des bancs de haute slikke dont la base est atteinte par les pleines mers de coefficient 100 dans les secteurs Ouest et seulement 90 à l'Est. A Chapelle Sainte-Anne, la submersion est quasi-totale par des coefficients de 100 alors que certains bancs formant la barrière littorale à Cherrueix et à Vildé-Hirel restent émergés même par coefficient 115 (hauteurs d'eau théoriques hors conditions dépressionnaires ni agitation). Cette barrière littorale de bancs bioclastiques ne peut être remaniée que par la conjonction d'épisodes de forte agitation avec des marées de vive-eau.

L'analyse d'une chronique de photos aériennes (14 missions espacées en moyenne de 5 ans) entre 1947 et 2006 (figure 8a) montre que les vitesses de migration des bancs depuis le bas estran jusqu'au trait de côte varient de plusieurs dizaines de mètres par an pour les bancs du moyen estran à quelques mètres par an pour ceux situés en bordure du schorre (figure $8 b$ ). 


\section{XII èmes Journées Nationales Génie Côtier-Génie Civil \\ Cherbourg, 12-14 juin 2012}
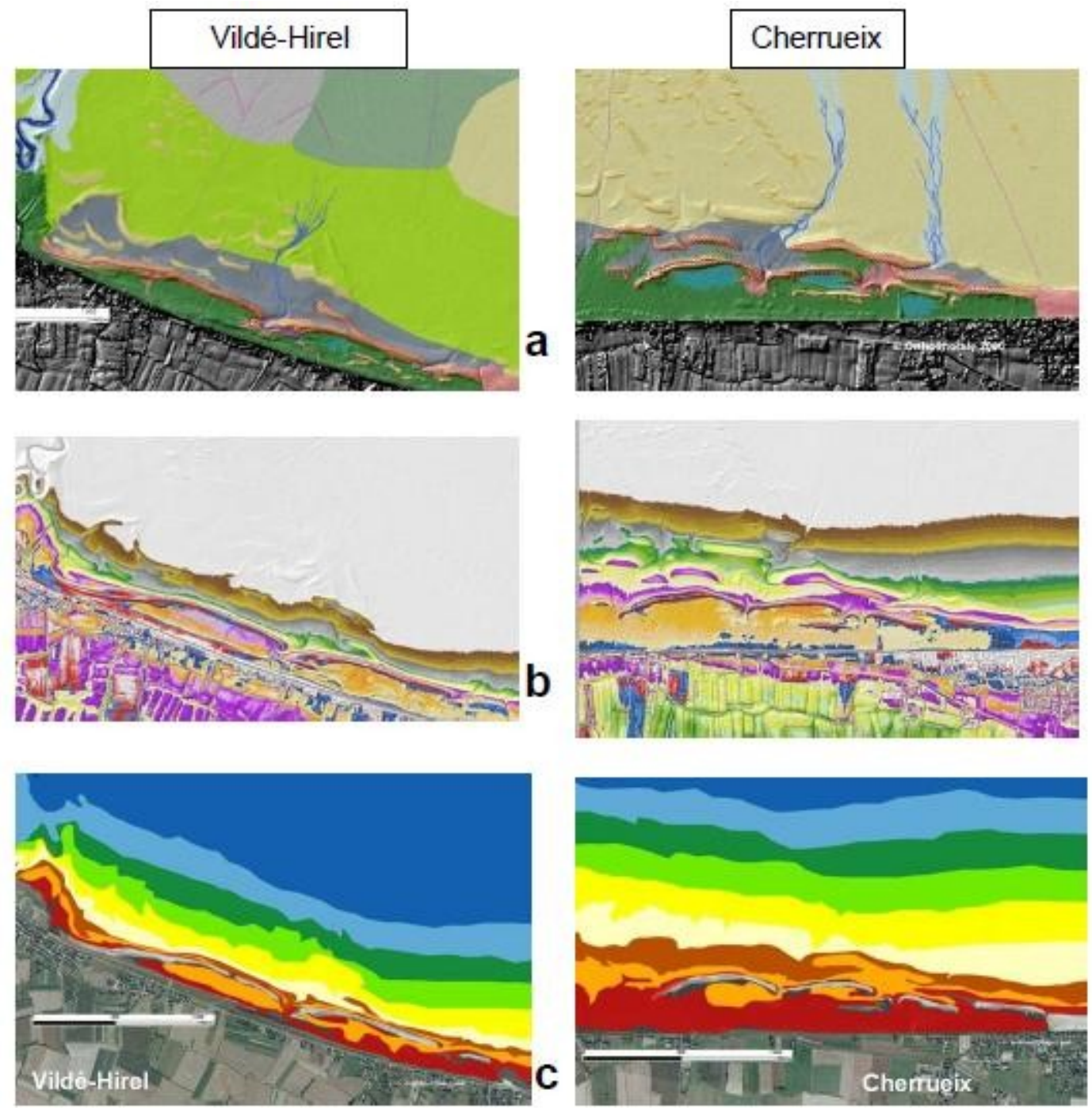

\begin{tabular}{|lll|}
\hline Cotes IGN & $\begin{array}{l}\text { Coefficient de } \\
\text { marée }\end{array}$ & $\begin{array}{l}\% \text { de depassement } \\
\text { ducoeff. sur l'ennée }\end{array}$ \\
\hline $44 \mathrm{~m}$ & & $65 \%$ \\
$4-4,5 \mathrm{~m}$ & $60[10,75 \mathrm{~m} \mathrm{CM})$ & $50 \%$ \\
$4,5-5 \mathrm{~m}$ & 70 & $42 \%$ \\
$5-5,5 \mathrm{~m}$ & 75 & $36 \%$ \\
$5,5-6 \mathrm{~m}$ & 80 & $20 \%$ \\
$6-6,5 \mathrm{~m}$ & 90 & $8 \%$ \\
$6,5-7 \mathrm{~m}$ & 100 & $3 \%$ \\
$7-7,5 \mathrm{~m}$ & 110 & $1 \%$ \\
\hline $7,5-8 \mathrm{~m}$ & $115(14,25 \mathrm{~m} \mathrm{CM})$ & \\
\hline$>8 \mathrm{~m}$ & & \\
\hline
\end{tabular}

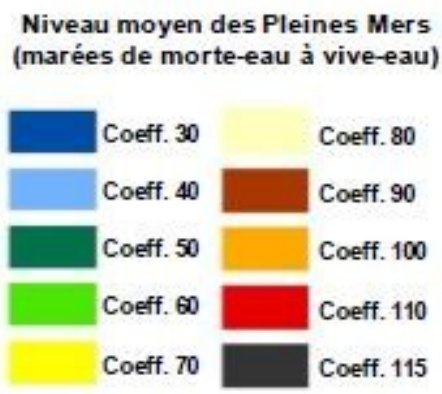

Figure 7. (a) Cartographie morpho-sédimentaire, (b) topographie Lidar et (c) niveaux de submersion des bancs coquilliers du haut estran de Vildé-Hirel et Cherrueix. 

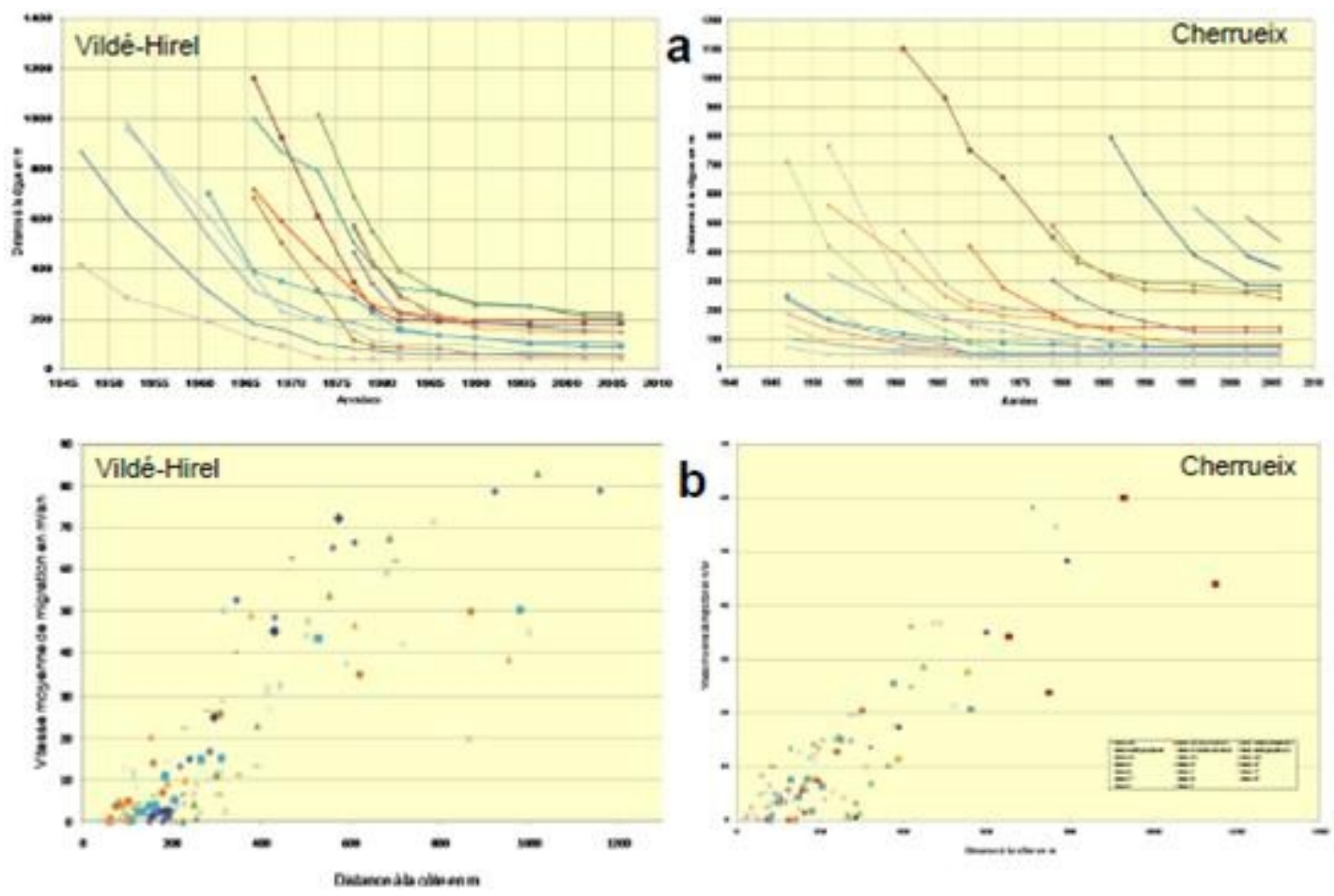

Figure 8. a :Migration des bancs vers le trait de côte entre 1947 et 2006 $\boldsymbol{b}:$ Vitesse de migration des bancs par rapport à leur position sur l'estran.

Pour une même distance à la côte, les vitesses de migration des bancs semblent diminuer d'Ouest en Est (figure 9), en fonction des différences de pentes entre l'estran de Vildé-Hirel, de Cherrueix et celui de Chapelle Sainte-Anne. En même temps que la largeur de la zone intertidale augmente vers la zone estuarienne, les pentes de l'estran s'adoucissent d'Ouest en Est. Ramenées aux cotes altimétriques de l'estran, les courbes de variations des vitesses de migration sont cohérentes entre les 3 secteurs. Au niveau du bas estran, les bancs migrent à des vitesses supérieures à $100 \mathrm{~m} / \mathrm{an}$ puis les vitesses diminuent régulièrement jusqu'à une cote de $5 \mathrm{~m}$ IGN où elles sont de l'ordre de $20 \mathrm{~m} / \mathrm{an}$. Au-dessus de $6 \mathrm{~m} \mathrm{IGN}$, la dynamique des bancs est ralentie, tombe à quelques $\mathrm{m} /$ an pour se stabiliser en barrière littorale à la limite du schorre.

La nature du sédiment le long du tidal flat, la pente de l'estran et les niveaux de submersion sont des facteurs déterminants dans la morphogenèse et l'évolution des accumulations bioclastiques de l'Ouest de la baie. L'absence d'accélération de la vitesse de migration des bancs dans la chronique de photos aériennes étudiée laisse penser que le facteur submersion lisse les évolutions brutales liées à des périodes de très forte agitation. 


\section{XII ${ }^{\text {èmes }}$ Journées Nationales Génie Côtier - Génie Civil \\ Cherbourg, 12-14 juin 2012}

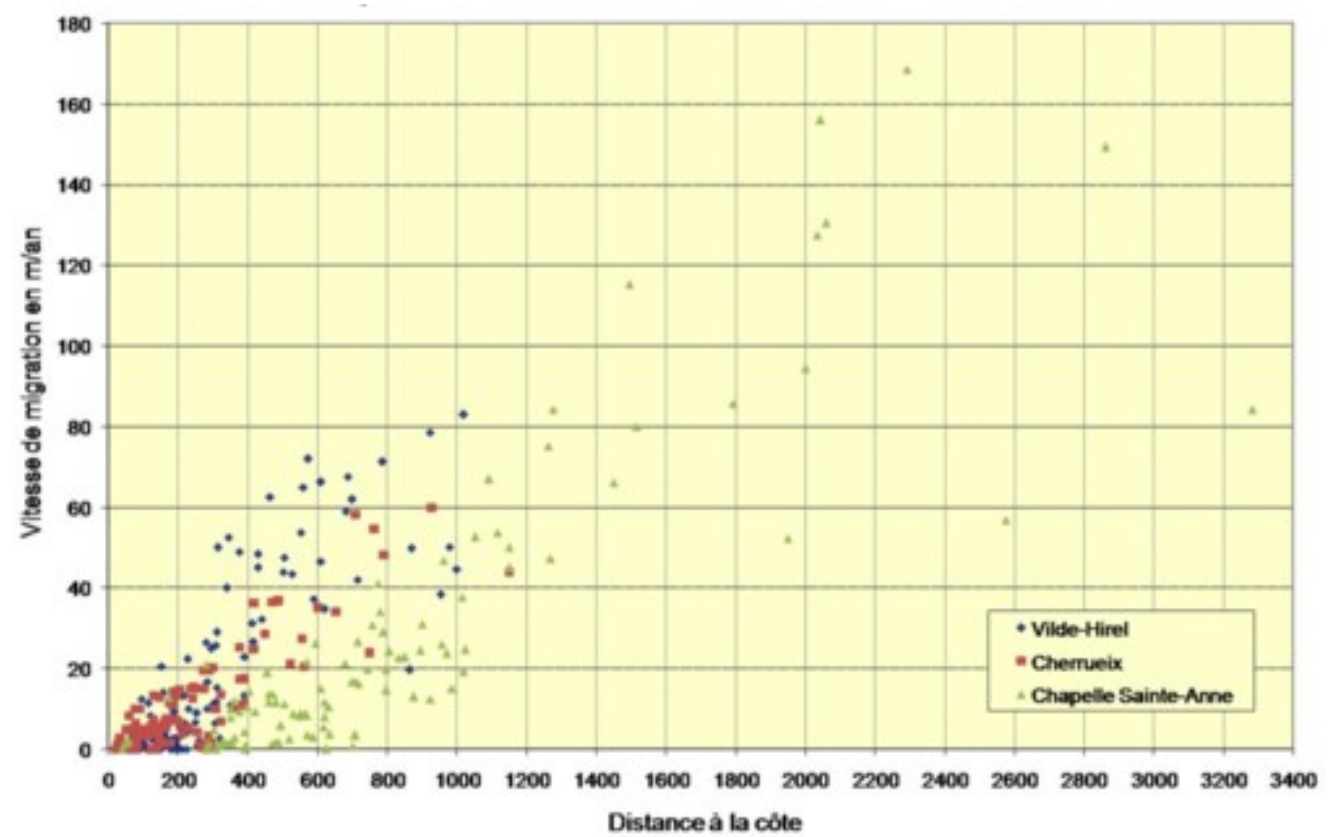

Figure 9. Vitesses de migration des bancs coquilliers en fonction de la distance à la côte.

La formation et l'évolution du système cordon littoral bioclastique - vasière arrière cordon dépendent de la durée potentielle d'action de la houle sur le haut estran et donc des niveaux de submersion tidale. Sur le bas et le moyen estran, les bioclastes carbonatés, de forme aplatie et de grande portance (WEILL, 2010), sont facilement mis en mouvement par de faibles houles et migrent rapidement sur le tidal flat sablo-vaseux alumino-silicaté. Lorsque ces bancs coquilliers arrivent sur le haut estran, ils s'accumulent sur place et deviennent suffisamment épais pour former une barrière littorale qui isole en arrière d'elle une micro-lagune abritée où se déposent des vases fines progressivement colonisées par la végétation halophile. A ce stade, les vagues ne peuvent plus franchir la crête du banc et, la dynamique de migration étant stoppée, il se stabilise. Lors de la conjonction de fortes houles avec des pleines mers de vive eau, ces bancs de bordure du schorre peuvent être remaniés par des processus de washover avec formation de lobes de débordement migrant vers la lagune arrière banc (WEILL et al. 2011). La mobilisation des éléments bioclastiques par les houles dépend de la submersion et les houles "douces" sont constructrices pour la barrière littorale. A l'inverse la conjonction d'une forte houle avec des pleines mers de vive eau peut entrainer la formation de brèches qui déstructurent la barrière littorale. 


\section{Processus hydro-sédimentaires et évolution des schorres aux abords du Mont- Saint-Michel}

\subsection{Interaction végétation - sédimentation et mise en place des schorres}

Dans la partie orientale de la baie du Mont-Saint-Michel, les schorres atteignent leur plus grand développement à partir de la Chapelle Sainte-Anne et ils s'étendent sur une largeur de près de $3 \mathrm{~km}$ sur le haut estran aux abords du Mont (LEFEUVRE et al.,1996). Les apports sédimentaires au front des herbus aux abords du Mont-Saint-Michel dépendent principalement du temps de submersion, donc de l'altitude du front de schorre, du contexte morpho-sédimentaire du front d'herbu et du niveau même du schorre ou de la slikke.

L'accrétion sédimentaire mesurée au front des schorres (BONNOT-COURTOIS et LEVASSEUR, 2002) varie en fonction du contexte morpho-dynamique de la haute slikke. En mode calme, la sédimentation de particules fines aboutit à des dépôts de 1 à $2 \mathrm{~cm} / \mathrm{an}$ au contact entre le bas schorre et la haute slikke. Les fronts de schorre situés en mode dynamique, plus exposé, peuvent subir des érosions souvent liées à la proximité d'un chenal (près de $20 \mathrm{~m}$ de recul de la bordure de l'herbu en une année) et les secteurs de la haute slikke situés en aval du transit des sables récupèrent de grandes quantités de sédiment avec un exhaussement pouvant atteindre $10 \mathrm{~cm} / \mathrm{an}$. L'accrétion sédimentaire diminue depuis la haute slikke jusqu'aux niveaux du moyen puis haut schorre où les valeurs sont de l'ordre du mm/an, ce qui confirme la pente inverse du schorre. Chaque espèce végétale s'installant en fonction de sa tolérance à la submersion, la répartition des formations végétales du schorre peut être directement reliée à la topographie tirée du levé Lidar (figure $10 \mathrm{a}$ et $\mathrm{b}$ ). L'accrétion sédimentaire est généralement importante sur la haute slikke. C'est donc d'abord le sédiment qui se met en place puis, lorsque le niveau altimétrique et donc la durée de submersion sont favorables, les plantes pionnières s'installent. La pérennité de l'existence d'un schorre ainsi que la dynamique de sa progression dépendent directement du contexte hydro-sédimentaire de la haute slikke qui le précède.

La mise en place puis la progradation d'un schorre est directement liée à des dispositions favorables qui nécessitent principalement :

- un niveau altimétrique compatible avec la tolérance à la submersion (en rythme et en durée cumulée) des espèces vivaces colonisatrices primaires ;

- un contexte morpho-sédimentaire et hydrodynamique propice à l'établissement des semences, et au maintien de conditions de protection nécessaires à la survie des jeunes plants, une fois leur germination effectuée. 


\section{XII ${ }^{\text {èmes }}$ Journées Nationales Génie Côtier - Génie Civil \\ Cherbourg, 12-14 juin 2012}

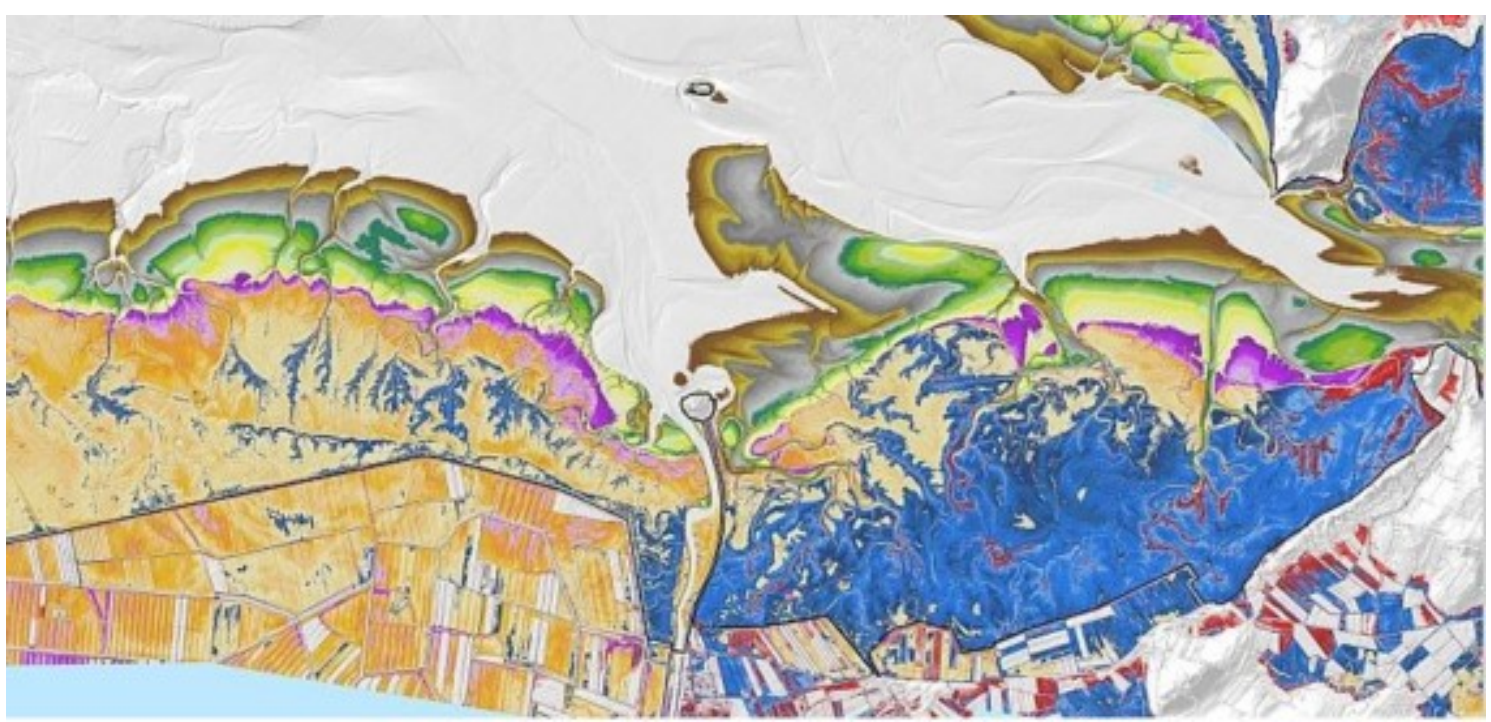

Figure 10 a. Topographie des schorres aux abords du Mont (levé LIDAR 2002).

\begin{tabular}{|c|c|c|c|}
\hline \multicolumn{2}{|c|}{ Cotes IGN } & $\begin{array}{l}\text { Coefficient de } \\
\text { marte }\end{array}$ & $\begin{array}{l}\text { \% de dépassement } \\
\text { du coeff. sur P'année }\end{array}$ \\
\hline & $<4 m$ & & \\
\hline & $4 \cdot 4,5 \mathrm{~m}$ & $60(10,75 \mathrm{~m} \mathrm{CM})$ & $65 \%$ \\
\hline & $4,5 \cdot 5 \mathrm{~m}$ & 70 & $50 \%$ \\
\hline & $5 \cdot 5,5 \mathrm{~m}$ & 75 & $42 \%$ \\
\hline & $5,5-6 \mathrm{~m}$ & 80 & $36 \%$ \\
\hline & $6 \cdot 6,5 \mathrm{~m}$ & 90 & $20 \%$ \\
\hline & $6,5-7 \mathrm{~m}$ & 100 & $8 \%$ \\
\hline & $7 \cdot 7,5 \mathrm{~m}$ & 110 & $3 \%$ \\
\hline & $7,5-8 \mathrm{~m}$ & $115(14,25 \mathrm{~m} \mathrm{CM})$ & 196 \\
\hline & $>8 \mathrm{~m}$ & & \\
\hline
\end{tabular}

\section{Schorre supérieur}

Végètabon prainele a Chiendent

Végétation prairiale à Féluque

Végetation dunaire

Végetsion prairiale saumbite à A.grosis

Yegetation seumätre â.Acrostis et Jonc de Gerard

Dépression salée irterne á Sal icome et Soude

Schorremoyen et infêrieur

Végétatan an sous-artustive dense à Obione Végélat un mine a Obione et Puconellie Végétat on praicial e basse a Puccinellie Végètat an fragnertée du schorre inférieut Faciés local à Soude etou Aster

\section{Haute slikke}

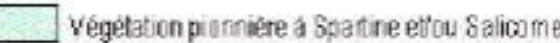

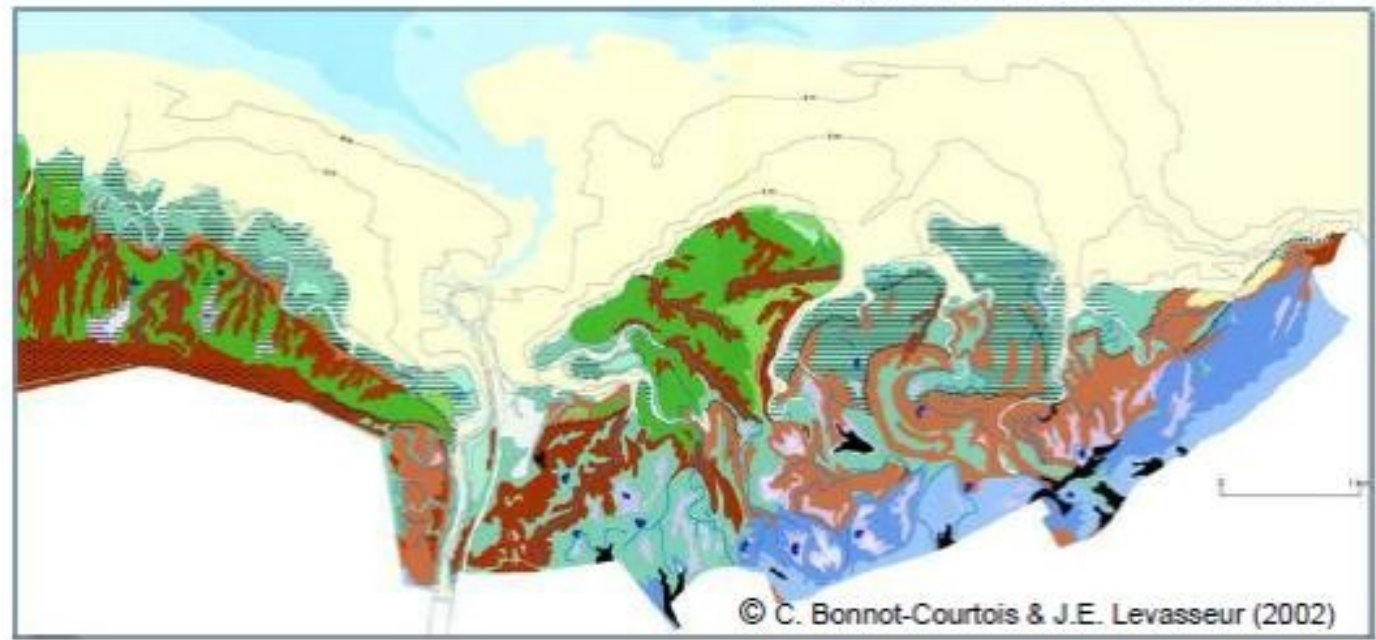

Figure 10 b. Répartition des formations végétales du schorre autour du Mont (Etat 1999). 
D'un point de vue général, les modalités d'édification d'un schorre se déclinent selon les phases suivantes (BONNOT-COURTOIS et LEVASSEUR, 2012) (figure 11) :

1) Initiation ou Edification : cette phase ne se déclenche que sous deux conditions, si possible réunies : une cote altimétrique $a d$ hoc et un mode d'exposition au moins semi-protégé.

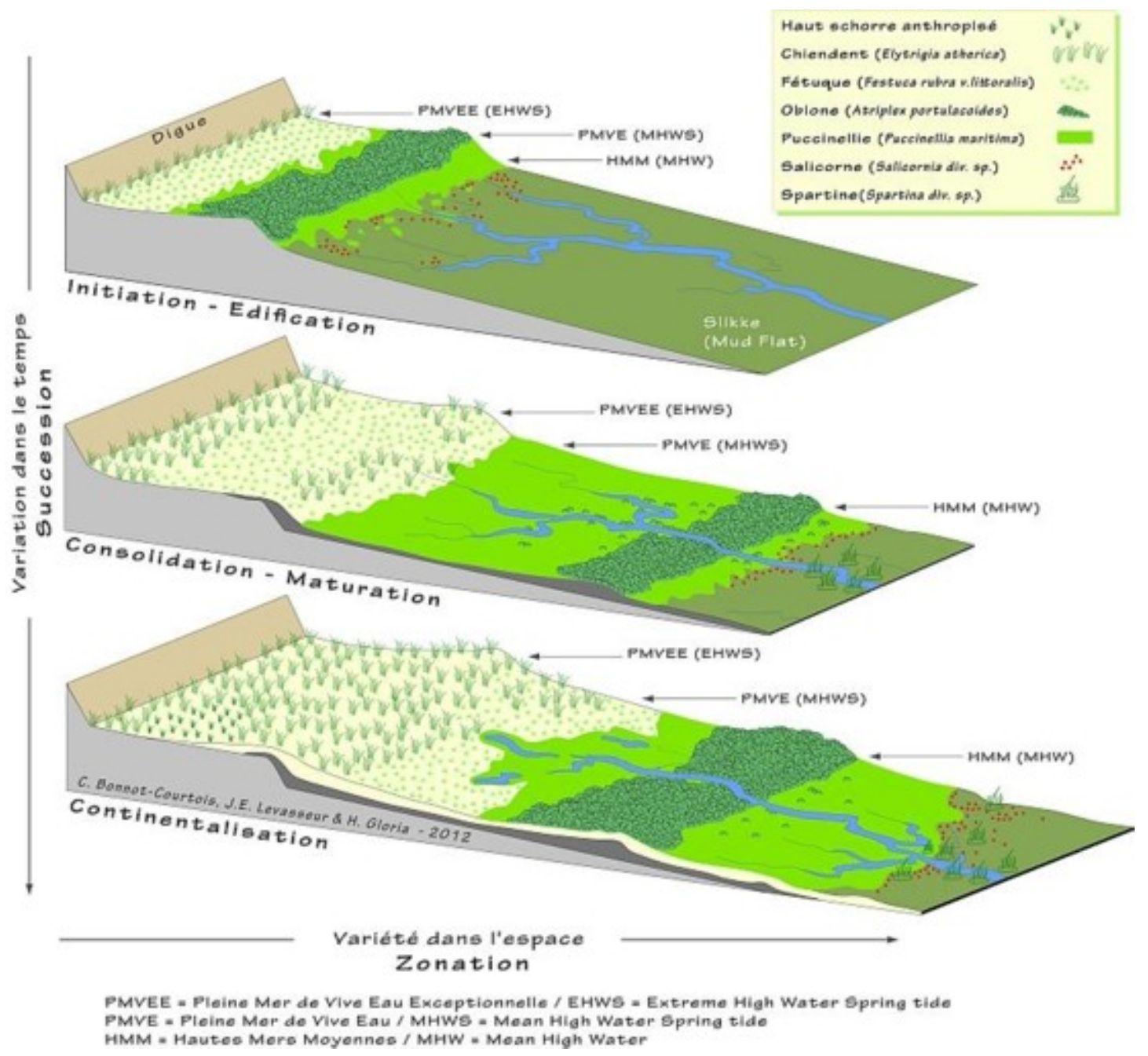

Figure 11. Les différentes phases d'évolution d'un schorre (BONNOT-COURTOIS \& LEVASSEUR (2012).

2) Consolidation : l'interaction entre les espèces pionnières (i.a. Puccinellie et p.p. Spartine) et la sédimentation au front des herbus se traduit par l'édification de petites buttes qui deviennent coalescentes. Puccinellia maritima devient dominante, mais cette phase est encore marquée par la présence d'espèces de la haute slikke.

3) Maturation : on assiste à une régularisation de la surface du marais, ce qui facilite la dominance de buissons à Atriplex portulacoides (Obione) qui, lorsque l'espèce n'est 


\section{XII ${ }^{\text {èmes }}$ Journées Nationales Génie Côtier - Génie Civil \\ Cherbourg, 12-14 juin 2012}

pas altérée par des facteurs de perturbation extérieurs, souvent anthropiques (LEFEUVRE et al. 2009), peut se maintenir de nombreuses années.

4) La Continentalisation clôt cette séquence. Elle se caractérise par le développement sur des terrains pratiquement hors d'atteinte des marées, d'espèces prairiales à très large potentiel de développement (Chiendent et Fétuque). Par rapport à 1999 (figure 10b), le Chiendent s'est développé de façon spectaculaire couvrant $73 \%$ du haut et moyen schorre à l'Ouest du Mont (LEFEUVRE et al. 2009).

\subsection{L'évolution des schorres (figure 12)}

L'analyse d'une chronique de photos aériennes (14 missions espacées en moyenne de 5 ans) entre 1947 et 2005 montre que la surface couverte par les herbus à l'Ouest du Mont a doublé en 50 ans (654 ha en 1947 et 1366 ha en 1996) et que la progression a été moins rapide à l'Est (634 ha en 1947 et 1049 ha en 1996).
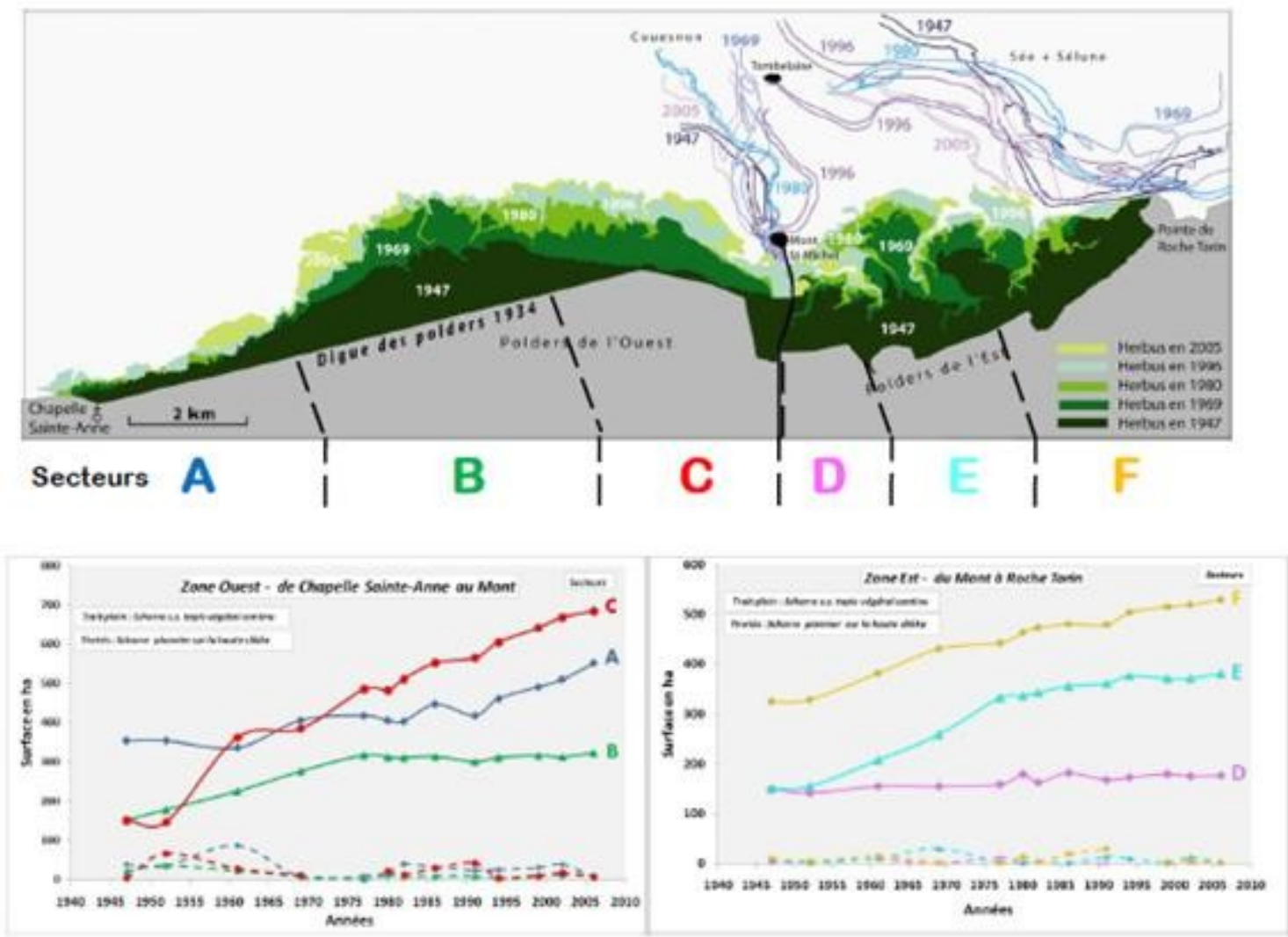

Figure 12. Progression et évolution de la surface des herbus entre 1947 et 2005.

La progression des schorres n'est pas équivalente pour tous les secteurs autour de Mont. La partie centrale des schorres de l'Ouest (secteur B) et la rive droite du Couesnon (secteur D) évoluent peu avec une progression lente et régulière du tapis végétal continu. Le secteur de La Chapelle Sainte-Anne (secteur A) évolue peu jusqu'en 1990 
puis prograde plus rapidement en raison de l'atterrissement de bancs sableux qui créent les conditions protégées favorables au développement de la végétation halophile pionnière sur la haute slikke. Le schorre de la rive gauche du Couesnon (secteur C) progresse rapidement et régulièrement pour passer de 150 ha en 1947 à 700 ha en 2005. Enfin, à l'Est du Mont, la progression des schorres de la zone du Grand Banc (secteur E) et celle de la Roche Torin (secteur F) a été importante entre 1947 et 1980 et s'est ralentie ensuite jusqu'en 2005. Actuellement, les schorres couvrent près de 2500 ha entre la Chapelle Sainte-Anne et la pointe de Roche Torin et la progression moyenne est de l'ordre de 15 à 20 ha par an.

\section{Evolution des paysages et Aménagements anthropiques}

Un socle très ancien de formations métamorphiques $(570 \mathrm{Ma})$ et de massifs granitiques (540 et $525 \mathrm{Ma}$ ) forme le substratum et les reliefs du pourtour de la baie du Mont-SaintMichel (L'HOMER et al. 1999). La configuration actuelle de la baie résulte de la remontée du niveau marin consécutive à la dernière déglaciation à partir de 18000 ans $\mathrm{BP}$. La transgression holocène comprend une première phase de remontée rapide du niveau marin qui passe de $-120 \mathrm{~m}$ à $-10 \mathrm{~m}$ en dessous du niveau actuel entre $18000 \mathrm{BP}$ et $6000 \mathrm{BP}(10 \mathrm{~mm} / \mathrm{an})$ puis une seconde phase plus lente à une vitesse moyenne de remontée du niveau marin de 1,5 mm/an (FAIRBANKS, 1989 in BILLEAUD 2007). Cette remontée générale du niveau marin n'est pas régulière mais est faite d'une succession d'oscillations positives ou négatives qui induisent des avancées et reculs de la ligne de rivage (MORZADEC-KERFOURN, 1975, 2002). A partir de $8000 \mathrm{BP}$, la mer envahit la baie et les apports sédimentaires vont progressivement combler le fond des estuaires et le marais de Dol où l'épaisseur des dépôts du prisme sédimentaire holocène peut dépasser $15 \mathrm{~m}$.

\subsection{Evolution historique des paysages de la baie}

L'évolution historique des paysages de la baie a été largement étudiée par Alain L'HOMER et a fait l'objet d'une exposition intitulée "Evolution de la baie autour du Mont depuis 708" à l'occasion du $13^{\text {ème }}$ centenaire de l'abbaye (L'HOMER et al. 2009). Les cartes présentées ci-dessous retracent les grandes étapes de la mise en place du littoral de la baie et sont des reconstitutions approximatives pour les périodes les plus anciennes antérieures au XVIIIème siècle. L'absence de données sur la période autour de l'an 708, date de fondation du Mont-Saint-Michel, a rendu nécessaire de remonter à la fin de l'Empire romain afin de disposer d'une base cartographique de départ (figure 13).

Des témoins archéologiques retrouvés dans des contextes sédimentaires différents constituent des marqueurs de l'occupation humaine du marais de Dol qui remonte à la fin de la période gauloise (BIZIEN-JAGLIN, 2002, 2008). Après de lourds combats impliquant trois légions romaines dans la région d'Avranches en 56 av. J.-C., les quatre 


\section{XII ${ }^{\text {èmes }}$ Journées Nationales Génie Côtier - Génie Civil \\ Cherbourg, 12-14 juin 2012}

tribus gauloises riveraines de la Baie sont définitivement intégrées à Rome à partir de 51 av. J.-C. (J-Y. COCAIGN, communication orale). De grandes voies à l'écart des côtes traversent ou convergent vers Legedia (Avranches). Des chemins côtiers au sud comme au nord desservent les ports d'échouage situés pour la plupart à l'embouchure des fleuves.

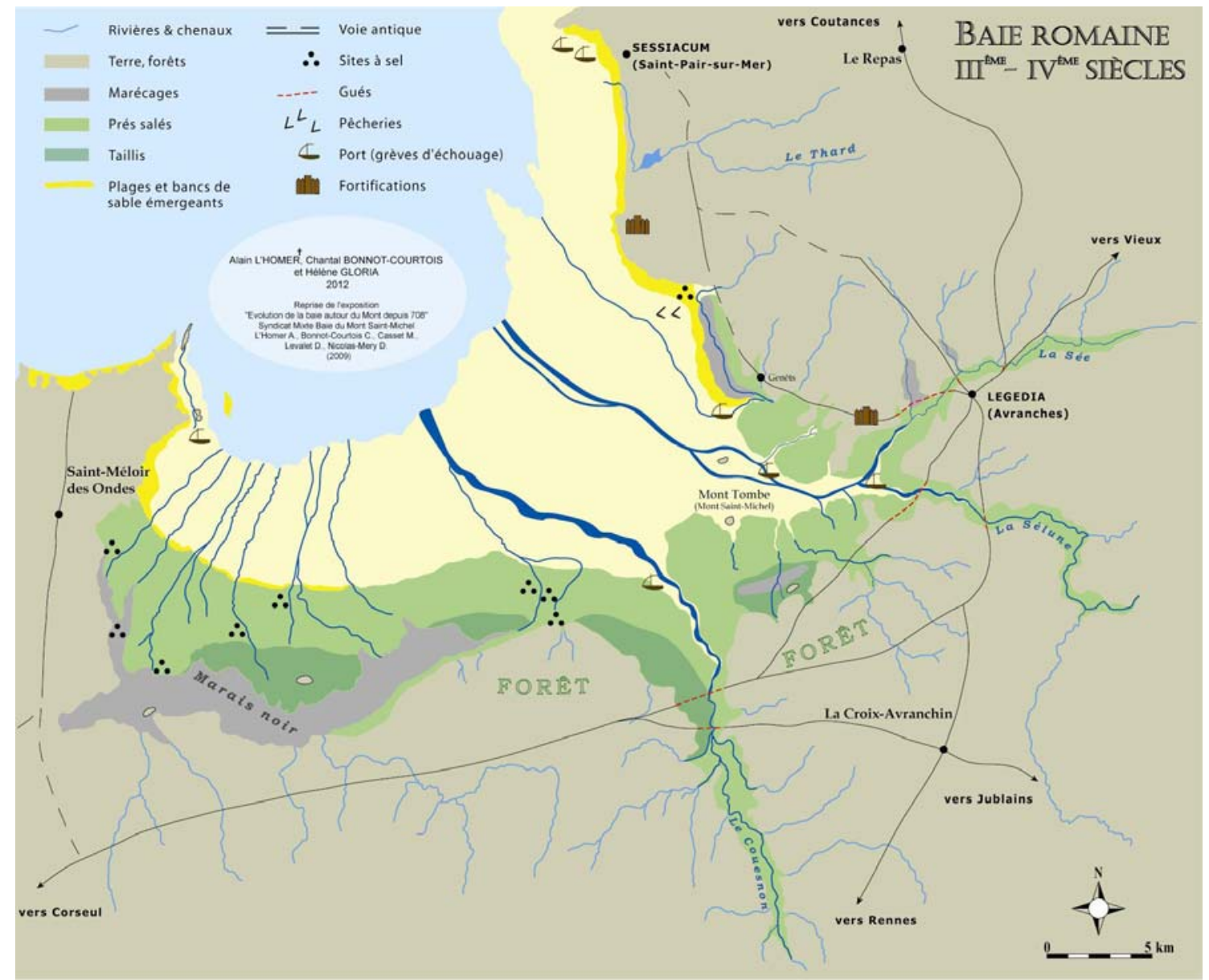

Figure 13. Reconstitution des rivages à l'époque romaine (L'HOMER, 2008).

Au Sud-Ouest, des cordons littoraux sableux se forment graduellement et bordent les prés-salés. Bien qu'étant régulièrement interrompus par les nombreux petits fleuves côtiers qui drainent l'arrière-pays, ces cordons sableux réduisent les entrées d'eau de mer dans les marais noirs du sud de la baie. Cette configuration de l'estran va favoriser l'implantation d'ateliers de bouilleurs de sel dans le marais de Dol, notamment à Rozsur-Couesnon, Hirel, La Fresnais et Saint-Méloir-des-Ondes. Ces sites à sel s'échelonnent du $1^{\text {er }}$ siècle avant JC au IVème siècle après JC (L'HOMER \& PIQUOIS, 2002). Dans le marais de Dol, ce type de fabrication du sel semble s'être arrêté suite à l'élévation rapide du niveau marin à partir du milieu du IIIème siècle. En dehors du sel, l'exploitation des richesses de la mer a laissé peu de traces (J.Y. COCAIGN, 
communication orale). Seules quelques grèves d'échouage sont signalées à Cancale et sur les estrans estuariens soumis à la divagation des fleuves et à d'importants courants. Les vestiges en bois d'un barrage à poissons, daté à plus de 3450 ans BP (fin de l'âge du Bronze) (L'HOMER, 1995) ont été découverts à Saint-Jean-le-Thomas lors d'une phase d'érosion importante ayant entrainé le démaigrissement de l'estran. Les pêcheries en bois et/ou en pierres implantées au pied des falaises de Champeaux témoignent d'une activité de pêche importante et très ancienne. Le site des Falaises comprend les vestiges de 9 barrages de pierres, datés du VIème au IXème siècle. Ces installations, soumises à un envasement rapide, ont vu un déplacement progressif vers l'Ouest entre le VIème et le XIIème siècle (BILLARD et al. 2006, BILLARD et al. (2012, à paraître, communication personnelle).

L'histoire de la baie du VIIIème au Xème siècle est profondément attachée à celle de l'Abbaye du Mont-Saint-Michel, à l'origine simple oratoire, fondée en 708 par Aubert alors évêque d'Avranches. Contrairement à l'interprétation d'un moine du XVème siècle indiquant que la forêt de Scissy avait été détruite par un raz de marée lors de la fondation du sanctuaire en 709, aucune forêt n'est présente avant cette date autour du Mont mais il existe toujours d'importants boisements en particulier dans la partie sud de la baie (BIZIEN-JAGLIN et L'HOMER, 2008).

En dehors des nombreux fleuves côtiers drainant la partie sud des marais de Dol, les cordons sableux et coquilliers limitent de plus en plus les entrées d'eau maritimes. Les premiers peuplements s'installent sur le cordon principal le plus au large. Dès le VIIIème, la baie estuarienne comprise entre l'estuaire du Couesnon de la Sée et de la Sélune va devenir un centre important de production de sel grâce à deux avancées techniques. L'exploitation et le lessivage du sablon salé des grèves de la baie estuarienne vont tout d'abord contribuer à accroître les quantités de saumures disponibles. La chauffe de cette saumure dans de grands récipients métalliques apportera l'évolution essentielle à l'amélioration de la productivité. La production de sel de la baie va également profiter pendant cette période et jusque vers 1150 de conditions climatiques très favorables (J.Y. COCAIGN, communication orale).

La période comprise entre le Xème et le XIIème siècle voit la création de villages côtiers comme Hirel, Cherrueix sur le cordon sableux fermant partiellement les marais de Dol. L'établissement de ces deux paroisses signalées pour la première fois en 1181 est nécessairement contemporain à la création d'une digue rehaussant le cordon sableux. Mais des entrées d'eau maritimes notamment aux débouchés des fleuves côtiers devaient encore subsister au XIIème siècle. Dans les marais protégés par cette digue, des verdières, champs enclos par de petites digues, sont signalés à l'ouest d'Hirel. Le point le plus fragile, et qui empêchera pendant des siècles la fermeture définitive du marais de Dol, se situe à l'est entre Cherrueix et les falaises de Saint-Broladre. Dans ce secteur, la dynamique sédimentaire et les divagations du Couesnon empêchent l'édification durable de cordons littoraux sableux contrairement à la partie sud-ouest de 


\section{XII ${ }^{\text {èmes }}$ Journées Nationales Génie Côtier - Génie Civil \\ Cherbourg, 12-14 juin 2012}

la Baie. Sur ces marais blancs aux sols fertiles, de nombreuses tentatives d'endiguement et de créations de verdières ( JORET, 2008) vont jalonner sans succès cette période et les périodes suivantes. A partir du XIIème, quelques établissements ruraux et même une paroisse, celle de Paluel, sont créés mais seront ensuite détruites par l'action conjuguée des marées et des divagations du Couesnon.

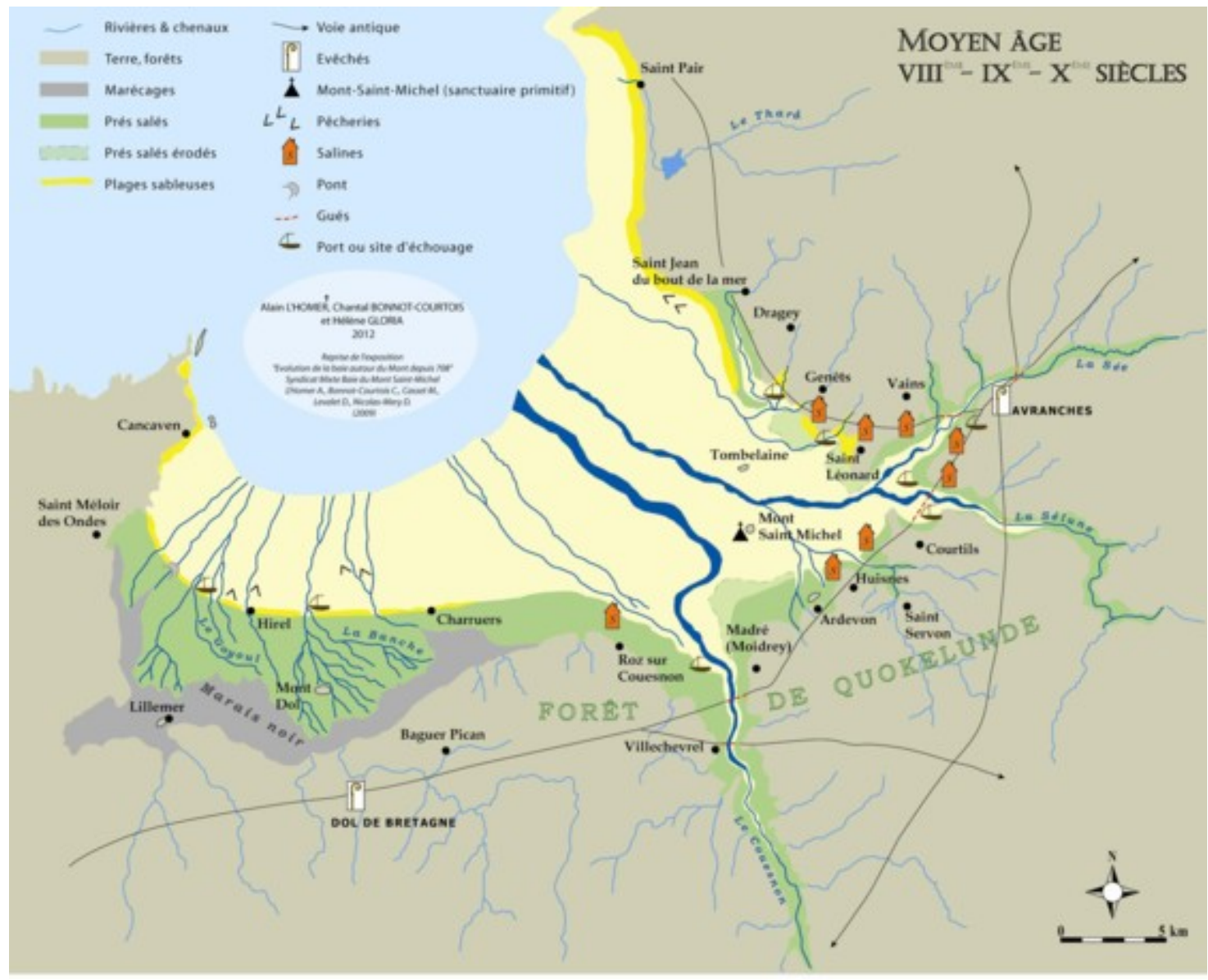

Figure 14. Les rivages de la baie au Moyen Age. Implantation des salines et activités maritimes (pêcheries, ports).

La relative stabilité des estrans au sud-ouest et au nord-est de la Baie favorise l'installation de nombreuses pêcheries. Profitant de la présence de platiers et de falaises schisteuses, quelques pêcheries en pierre sont implantées en contrebas des falaises de Saint-Jean et ces installations vont connaître un déplacement vers le Nord-Ouest particulièrement important au Xème et XIème siècle. Le site des Falaises est abandonné au profit du site de Sol Roc où se trouvent deux générations de pêcheries : celle actuellement couverte d'Hermelles remonte au XII-XIIIème siècle et est abandonnée au XVème siècle pour une autre installation plus proche de la côte (BILLARD, communication orale). Sur les estrans sableux du sud-ouest, la technique des pêcheries 
en bois sera privilégiée et un premier groupe de pêcheries les plus occidentales serait antérieur au XIème siècle. En face de Vildé-la-Marine, la ligne de pêcheries actuelle remonterait en partie au XIIIème siècle par abandon des premières pêcheries (LANGOUET, 1995).

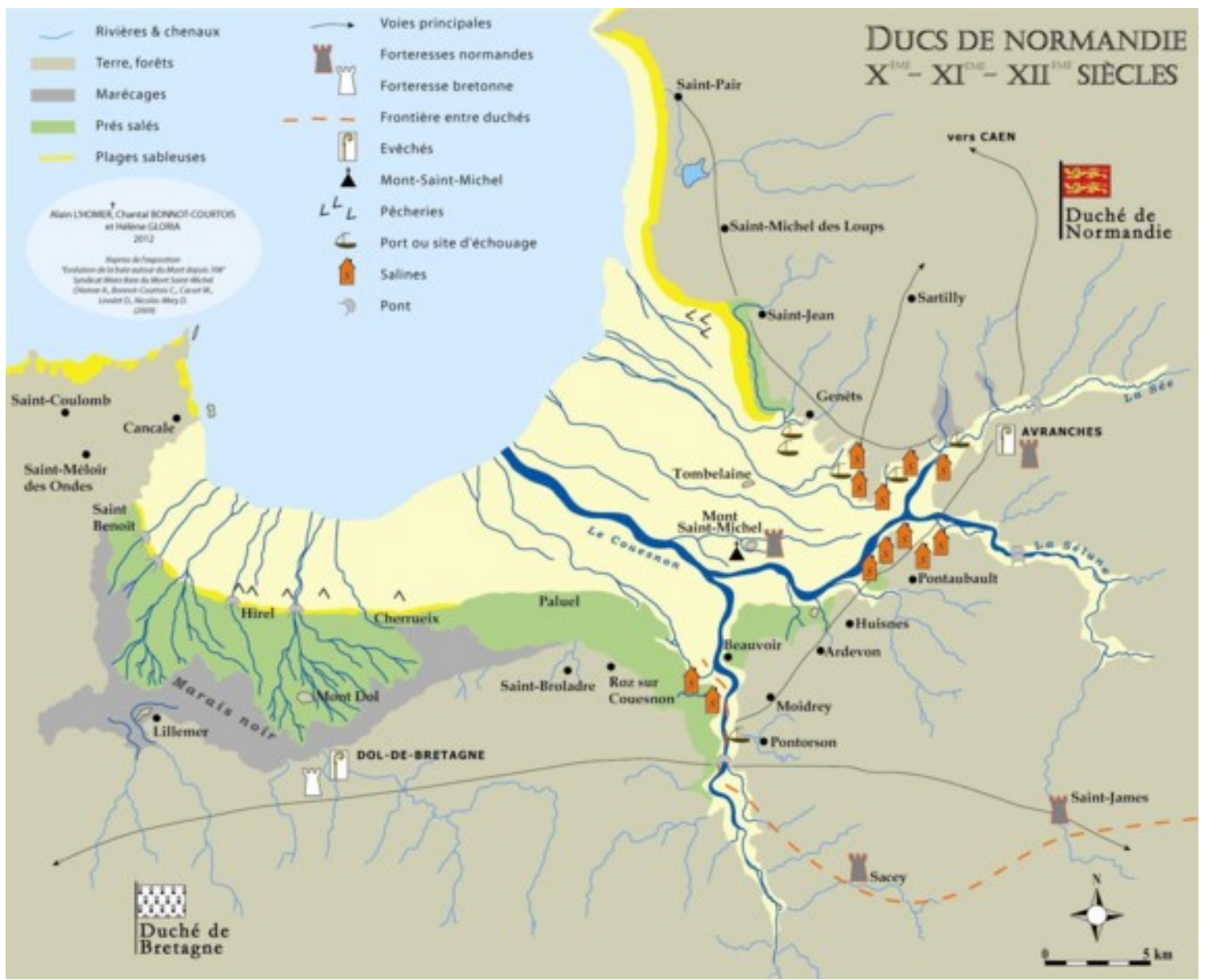

Figure 15. Les rivages de la baie autour du XIème siècle.

Entre le Xème et le XIIème puis au cours des siècles suivants, la baie estuarienne voit l'implantation des salines s'accélérer. Les sablons récupérés sur l'estran puis débarrassés de leur sel par lessivage sont peu à peu entassés à proximité des salines et vont contribuer jusqu'au XIXème à la création de vastes et souvent hautes digues sableuses, appelées "mondrins". La ligne de rivage de la baie estuarienne sera alors définitivement modifiée puisque les marais seront protégés des incursions marines par ces accumulations de tangue (figure 16). 


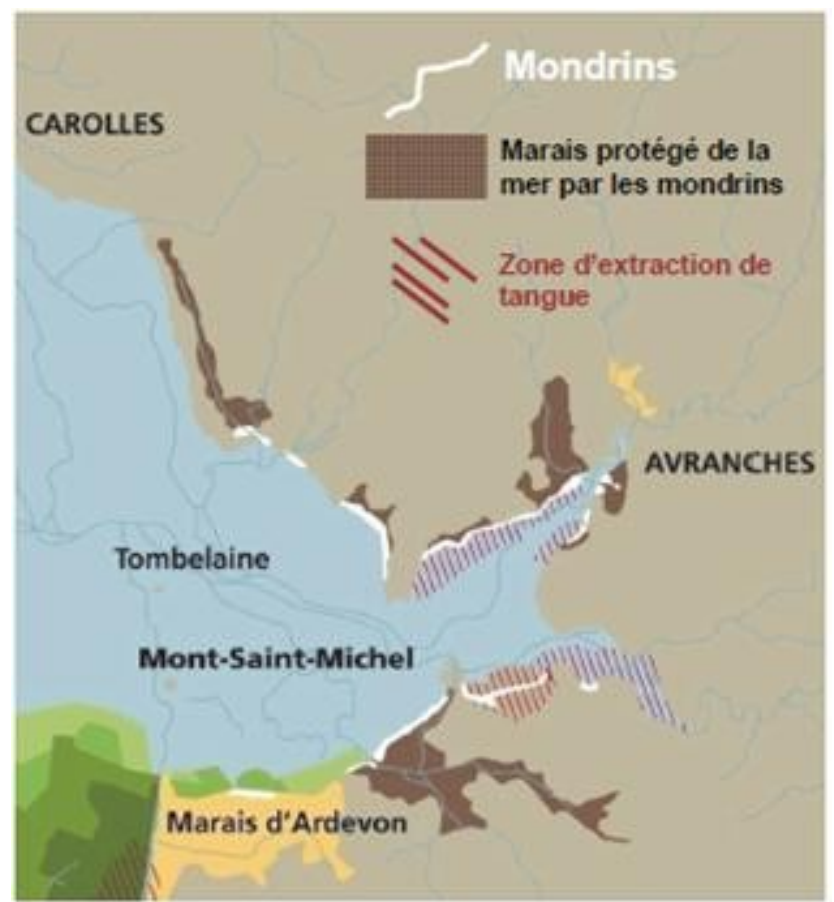

Figure 16. Mondrins ou anciennes accumulations de sables liés à la fabrication du sel de l'Avranchin et protégeant des marais des incursions marines (J.Y. COCAIGN, communication personnelle. Extrait de l'exposition «La Baie au travers des âges »

Ecomusée de la baie du Mont-Saint-Michel. CG50)

Deux barrières successives ont permis d'isoler le marais de Dol du domaine littoral au cours du Moyen Age (figure 17). Le cordon interne, le plus ancien, présente de nombreuses brèches assez larges laissant supposer des pénétrations importantes d'eau de mer dans le marais. L'édification de ce premier cordon remonterait au VIème siècle et se serait poursuivie jusqu'au VIIIème siècle (L'HOMER et al. 1995). Le deuxième cordon se serait formé à partir du IXème siècle pendant lequel de nombreuses submersions marines sont signalées.

La digue de la Duchesse Anne, construite sur ce deuxième alignement d'anciens cordons coquilliers, fixe le trait de côte et isole le marais de Dol des incursions marines. Le niveau topographique du marais est inférieur au niveau du haut estran et la pente du marais étant inverse, les parties les plus internes du marais noir sont situées $4 \mathrm{~m}$ plus bas que le marais blanc, lui-même 1 à $2 \mathrm{~m}$ plus bas que le haut estran actuel. 


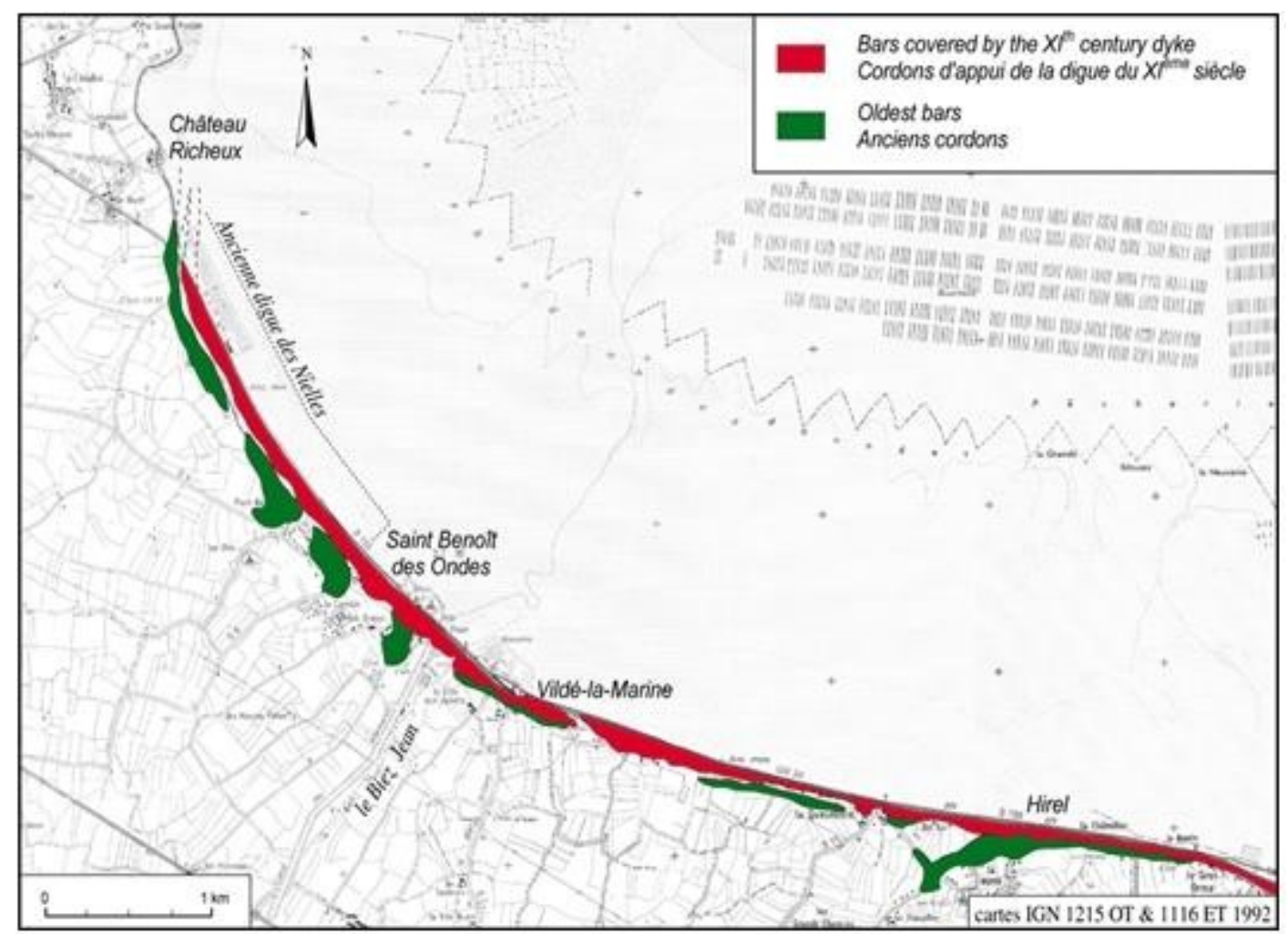

Figure 17. Cordons littoraux anciens dans la partie occidentale de la baie entre Château Richeux et Hirel.

A la fin du XVIIIème siècle, la carte de la famille Cassini, dressée par ordre du roi, est la première carte générale de la France. Elle comporte 181 feuilles dont les levés ont été effectués entre 1756 et 1789 . La feuille $N^{\circ} 127$, publiée en 1759 , couvre le littoral entre Saint-Malo et Granville et présente la baie du Mont-Saint-Michel, largement découvrante et parcourue par quelques chenaux principaux. A l'Ouest, deux débouchés à Saint-Benoît des Ondes et au Vivier correspondent à la jonction de petits fleuves côtiers qui suivent un tracé rectiligne orienté au Nord. A l'Est, débouchent les trois principaux fleuves de la baie : le Couesnon, la Sée et la Sélune qui s'écoulent en direction du Nord-Ouest. Avant les aménagements autour du Mont, la marée pouvait remonter dans un large système estuarien formé par le chenal commun de la Sée et de la Sélune et par celui du Couesnon (figure 18). Les chenaux de ces estuaires "sauvages" pouvaient divaguer avec un débattement potentiel de $4 \mathrm{~km}$ de part et d'"autre d'une ligne reliant le Mont à La Chapelle Sainte-Anne (L'HOMER, 2002). 


\section{XII èmes Journées Nationales Génie Côtier - Génie Civil \\ Cherbourg, 12-14 juin 2012}

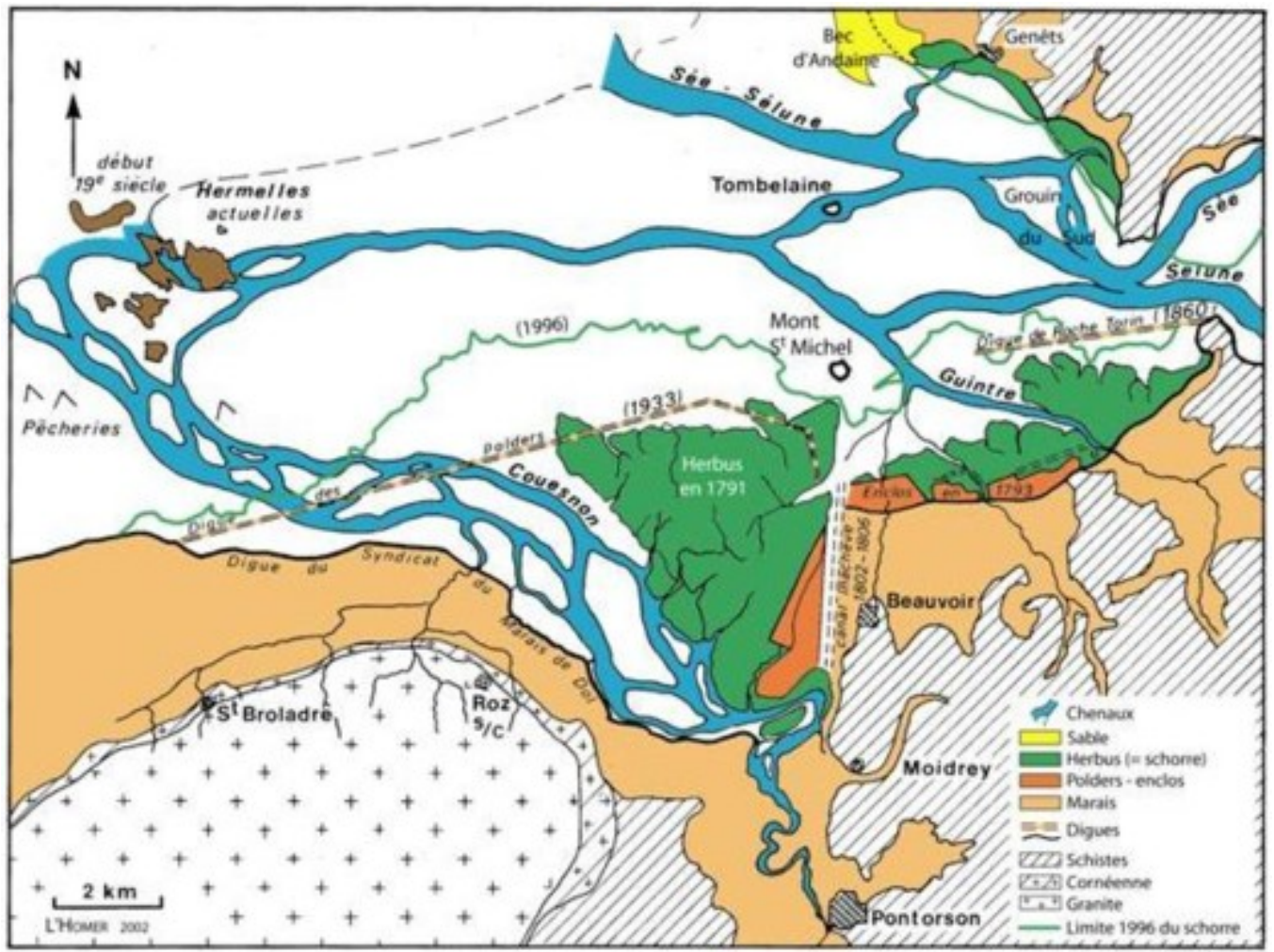

Figure 18. Configuration de la zone estuarienne à la fin du XVIIIème.

En 1771, les ingénieurs géographes ont pour mission de dresser "la carte topographique des côtes de France... depuis le Mont-Saint-Michel jusqu'à l'île de Noirmoutier". La précision des levés et la qualité de représentation de tous les éléments du paysage feront de cette carte une référence pour les côtes bretonnes. En Baie du Mont-Saint-Michel, les levés sont effectués au printemps 1775 et les niveaux de marées, "laisses de haute-mer de vive-eau", y sont indiqués avec grande précision. Immédiatement à l'Ouest du Mont, le vaste terrain indiqué comme "mollières ou pâturages qui couvrent dans les grandes marées d'équinoxe" est un herbu qui a colonisé les sédiments accumulés sur la rive droite du Couesnon. A son extrémité Nord-Est, la bordure de l'herbu se trouve seulement à 370 mètres du Mont. Au Sud-Est, en bordure du chemin qui mène de Pontorson au Mont, un enclos entouré de digues a été réalisé au niveau de Beauvoir (figure 18). Le Couesnon débouche dans la baie au niveau de La Chapelle Sainte-Anne (JORET, 2008) et s'écoule vers le Nord-Ouest en direction du banc des Hermelles. Depuis l'anse de Moidrey, le chenal longe la digue du Syndicat du marais de Dol qui protège le marais au pied du massif granitique de Saint-Broladre. Dans la zone estuarienne, les chenaux de la Sée, de la Sélune et des petits cours d'eau compris entre le Mont et la pointe de Roche Torin (la Guintre, le Landais, la Rive) divaguent largement sur l'estran et encerclent le Mont-Saint-Michel et l'îlot Tombelaine (figure 20). 


\subsection{Les aménagements depuis le XVIIIème siècle}

\subsubsection{Les pêcheries}

Dans la partie occidentale de la baie, la ligne presque continue des pêcheries en bois a été densifiée au XVIIème siècle pour atteindre une quarantaine de pêcheries sur l'ensemble du moyen estran. Leur expansion vers l'est a été limitée par les forts courants de marées et les divagations du Couesnon qui s'écoulait alors vers le Nord-Ouest.

Le rôle de piège sédimentaire joué par ces installations est clairement visible dans le décalage des niveaux altimétriques, entre l'intérieur des pêcheries et l'estran extérieur. Ces pêcheries sont comprises entre les basses mers de coefficient 40 et 50, soit en moyenne 4,5m au-dessus du 0 hydrographique (- 2,5m IGN) (figure 19).

Le fonctionnement des anciennes pêcheries en pierres de Champeaux entraîne également des accumulations sédimentaires importantes à l'intérieur des barrages à poissons, d'autant qu'il n'existait pas encore de porte amovible permettant d'effectuer des vidanges et des érosions par les courants de jusant (BILLARD, 2012).
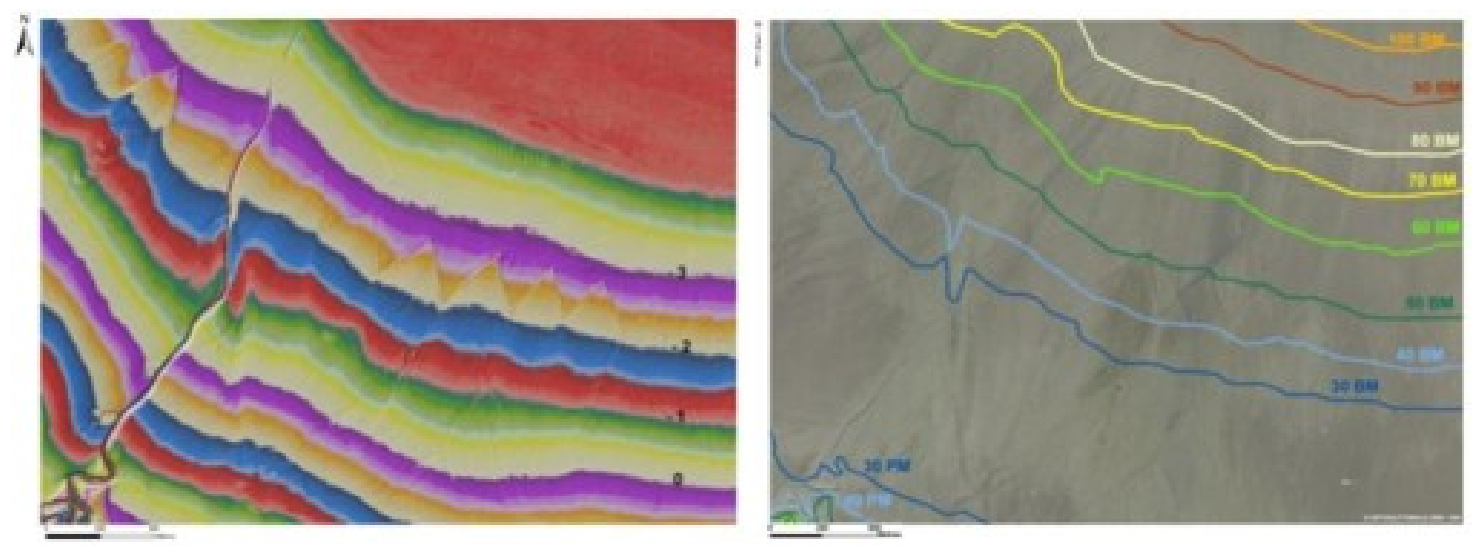

Figure 19. Topographie Lidar et niveaux de marée autour des pêcheries à Vildé la Marine

\subsubsection{La Conchyliculture (figure 20)}

Les grandes étapes de l'implantation de l'ostréiculture en baie du Mont-Saint-Michel sont les suivantes :

XVIIIème siècle : Exploitation par dragage des bancs naturels d'huîtres plates XIXème siècle : Elevage d'huîtres plates à Cancale 1906 : Premières concessions ostréicoles en zones découvrantes sur le moyen et bas estran de Cancale 1959 : Introduction de l'huître portugaise puis japonaise De 1970 à 1996 : Nouvelles concessions ostréicoles en eau profonde (figure 20). 


\section{XII ${ }^{\text {èmes }}$ Journées Nationales Génie Côtier - Génie Civil \\ Cherbourg, 12-14 juin 2012}

L'impact principal de la culture des huîtres dans des poches sur tables pour les concessions en zones découvrantes est un ralentissement des courants et un exhaussement du niveau de vase fine sous les installations (SORNIN, 1981 ; NIKODIC, 1981). Lors de la restructuration conchylicole de 2004, les parcs ostréicoles les plus envasés ont été transférés plus à l'Est à la place des bouchots en face de Vildé.

La mytiliculture a été introduite dans la baie en 1954 de part et d'autre du chenal du Vivier par les boucholeurs charentais de l'anse de l'Aiguillon (VERGER et LE VOT, 2002). A partir de 1960, les lignes de bouchots se sont largement étendues entre le chenal du Biez Jean à Saint-Benoît des Ondes et le banc des Hermelles, avec, en 1977, un développement de l'exploitation des bouchots par l'utilisation de bateaux amphibies. Entre 1975 et 1980, de nouvelles concessions mytilicoles ont été établies au large du banc des Hermelles, et en 2004, les bouchots de Vildé, remplacés par les tables ostréicoles, ont été transférés au Nord-Est des Hermelles dans la zone de divagation des chenaux estuariens (figure 20).

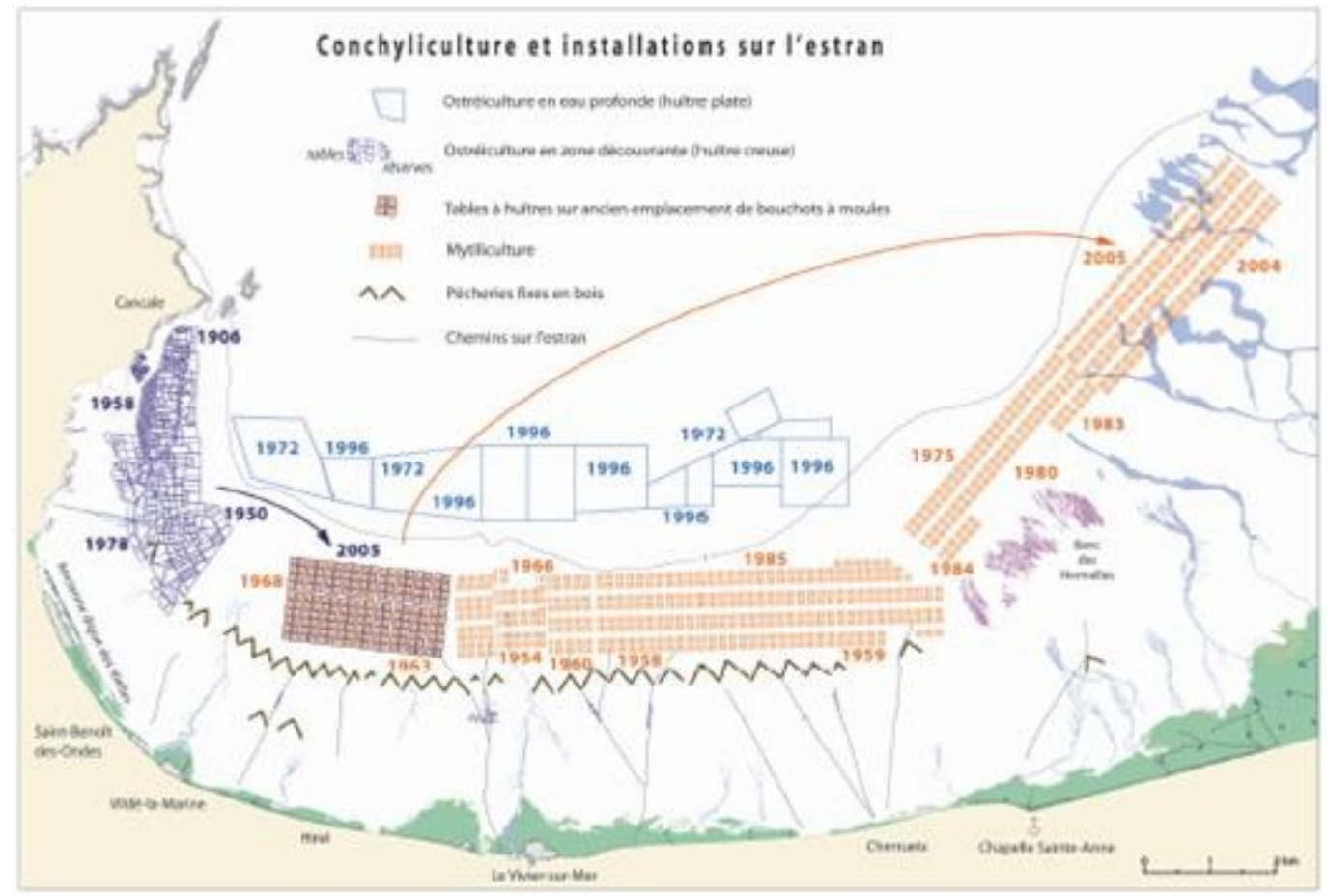

Figure 20. Conchyliculture et installations sur l'estran occidental entre Cancale et La Chapelle Sainte Anne.

L'implantation de la conchyliculture sur l'ensemble du bas estran occidental peut avoir des conséquences très variables sur la sédimentation. D’une part, la culture des huitres sur tables provoque une augmentation de l'envasement sous les tables. D'autre part, la densité des lignes de bouchots entraine une canalisation des courants qui sont renforcés entre les pieux mais la production de bio-dépôts augmente la teneur en fraction fine du 
sédiment. Les pêcheries fixes du moyen estran constituent des pièges où s'accumulent les vases fines particulièrement entre Vildé la Marine et Le Vivier-sur-mer.

\subsubsection{Les endiguements et la poldérisation}

La conquête de terres sur la mer par l'assèchement des marais maritimes et leur endiguement remonte au XIIème dans le marais de Dol (BIZIEN-JAGLIN, 2008; JORET, 2008). A l'Ouest, la digue de la Duchesse Anne fixe le trait de côte entre Château Richeux et La Chapelle Sainte-Anne dès le XIème siècle. Elle se prolonge vers l'Est jusqu'à Moidrey par une succession de digues, par endroits doublées de contredigues et renforcées par des éperons, qui protègent les marais au pied du massif de Saint-Broladre et dont les plus anciennes ont été construites avant le XVIIème siècle SACHET (2008).

Les premiers endiguements autour du Mont datent de la fin du XVIIIème siècle (figure 21). Les premiers projets de digue, déposés en 1757 englobaient une très large surface de l'estran entre l'anse de Moidrey, l'îlot Tombelaine et la pointe de Roche Torin. En 1769, un nouveau projet de digues, d'emprise plus restreinte autour du Mont, est demandé par Quinette de la Hogue, un armateur granvillais. En 1777, les Services du Comte d'Artois (futur Charles X) déposent un nouveau projet de concessions prenant appui sur le Mont, pour faire échec aux tentatives d'endiguements de Quinette de la Hogue (figure 21).

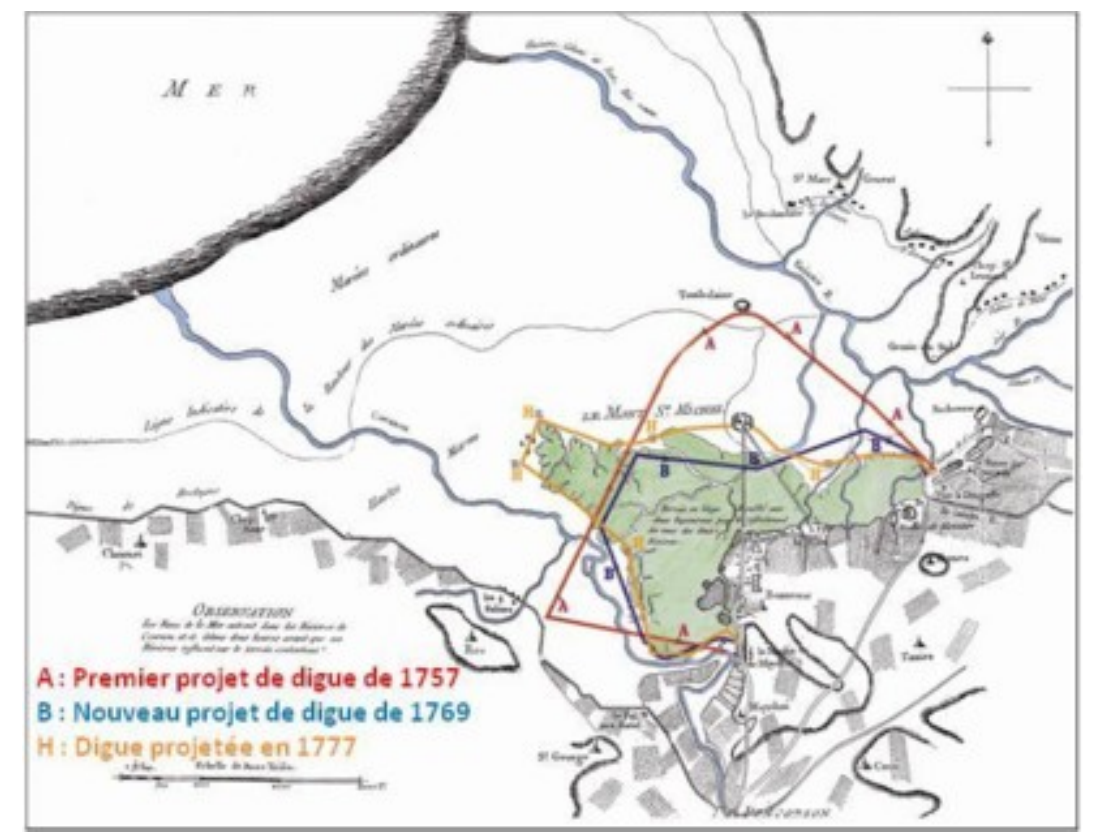

Figure 21. Les premiers projets d'endiguements autour du Mont.

Au tout début du XIXe siècle, l'embouchure du Couesnon se situait dans l'anse de Moidrey et le chenal principal s'écoulait vers le Nord-Ouest, en longeant la digue des 


\section{XII ${ }^{\text {èmes }}$ Journées Nationales Génie Côtier - Génie Civil \\ Cherbourg, 12-14 juin 2012}

marais située en contrebas du massif de Saint-Broladre. Périodiquement déstabilisés par les courants de marée et les apports sédimentaires, le chenal du Couesnon et les chenaux de marée attaquent alternativement les digues empierrées du littoral breton à l'Ouest, entre 1805 et 1817, puis dévastent les digues en terre des enclos récents des rivages normands proches du Mont entre 1817 et 1833 (figure 22). Une première tentative de canalisation du Couesnon en 1805 se solda par un échec.

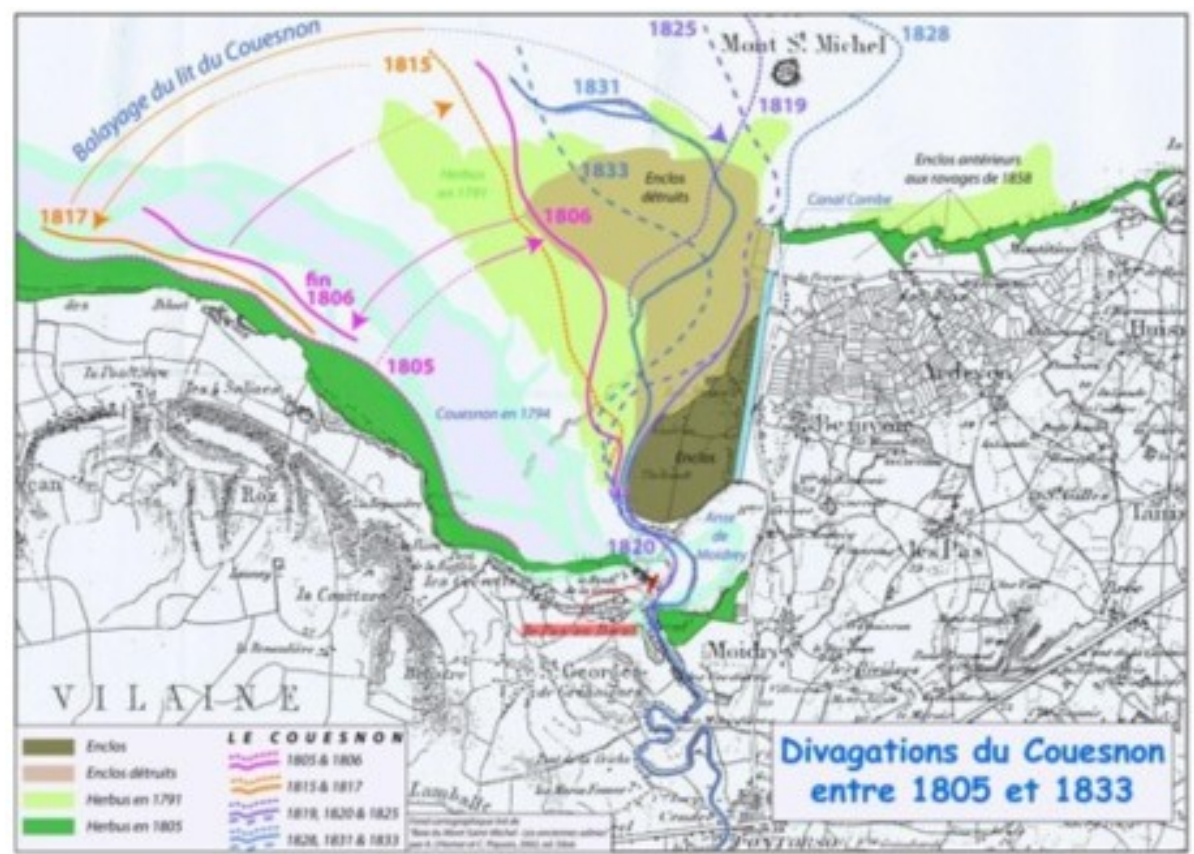

Figure 22. Divagations du Couesnon au début du XIXème siècle avant sa canalisation

Pendant la première moitié du XIXème siècle, les divagations du Couesnon provoquent de nombreuses ruptures de digues, détruisant tous les premiers enclos. En 1856, la Compagnie Mosselmann \& Donon obtient l'accord de l'Etat pour la poldérisation de 4350 ha autour du Mont, à charge pour la Compagnie de réaliser la canalisation du Couesnon.

Les grandes étapes de la poldérisation se succèdent selon la chronologie suivante :

1858 : Dérivation du Couesnon par la Compagnie Mosselmann par l'édification d'un barrage en terre, dit du Pas-aux-bœufs, à Moidrey (figure 22) ;

1863 : Canalisation du Couesnon sur une longueur de $3800 \mathrm{~m}$ à partir de l'anse de Moidrey ;

1857 à 1861 : Construction de la digue de Roche Torin, prenant appui sur la pointe de Roche Torin au débouché de la Sélune et initialement prévue pour aller jusqu'au Mont. Cette digue devait repousser vers le Nord le chenal commun de la Sée-Sélune afin de pouvoir poldériser à l'Est du Mont. 
1867 : Abandon du projet de concession à l'Est du Mont en raison de la difficulté des travaux liée à la divagation des chenaux. La compagnie Mosselmann devient alors la Compagnie des Polders de l'Ouest.

1868 : Ruptures des digues en terre et envahissement des premiers polders de l'Ouest par la mer. L'empierrement de la digue de ceinture sera alors préconisé suite à ces tempêtes.

1878-1879 : Construction de la digue route insubmersible d'accès au Mont

1879 à 1884 : Détournement des petits cours d'eau (La Guintre, La Rive et Le Landais) à 1 'Est du Mont

1906, 1928 et 1947-49 : Poldérisation à 1 'Est du Mont

1914 : Obtention par les Beaux-Arts du déplacement vers le Sud de la limite de concession des polders de l'Ouest, initialement prévue pour aller jusqu'au Mont.

1933 - 1934 : Construction de la digue de ceinture des polders de l'Ouest, dans l'alignement du Mont.

La conquête de terres sur la mer aux abords du Mont (figure 23) n'a donc pu être réalisée que lorsque la canalisation réussie du Couesnon en 1863 a permis la poldérisation de son ancien estuaire. Les conquêtes successives, réalisées parallèlement à la progression des schorres, sont marquées par un réseau de digues édifiées grâce au travail considérable des ouvriers de la Compagnie Mosselmann.
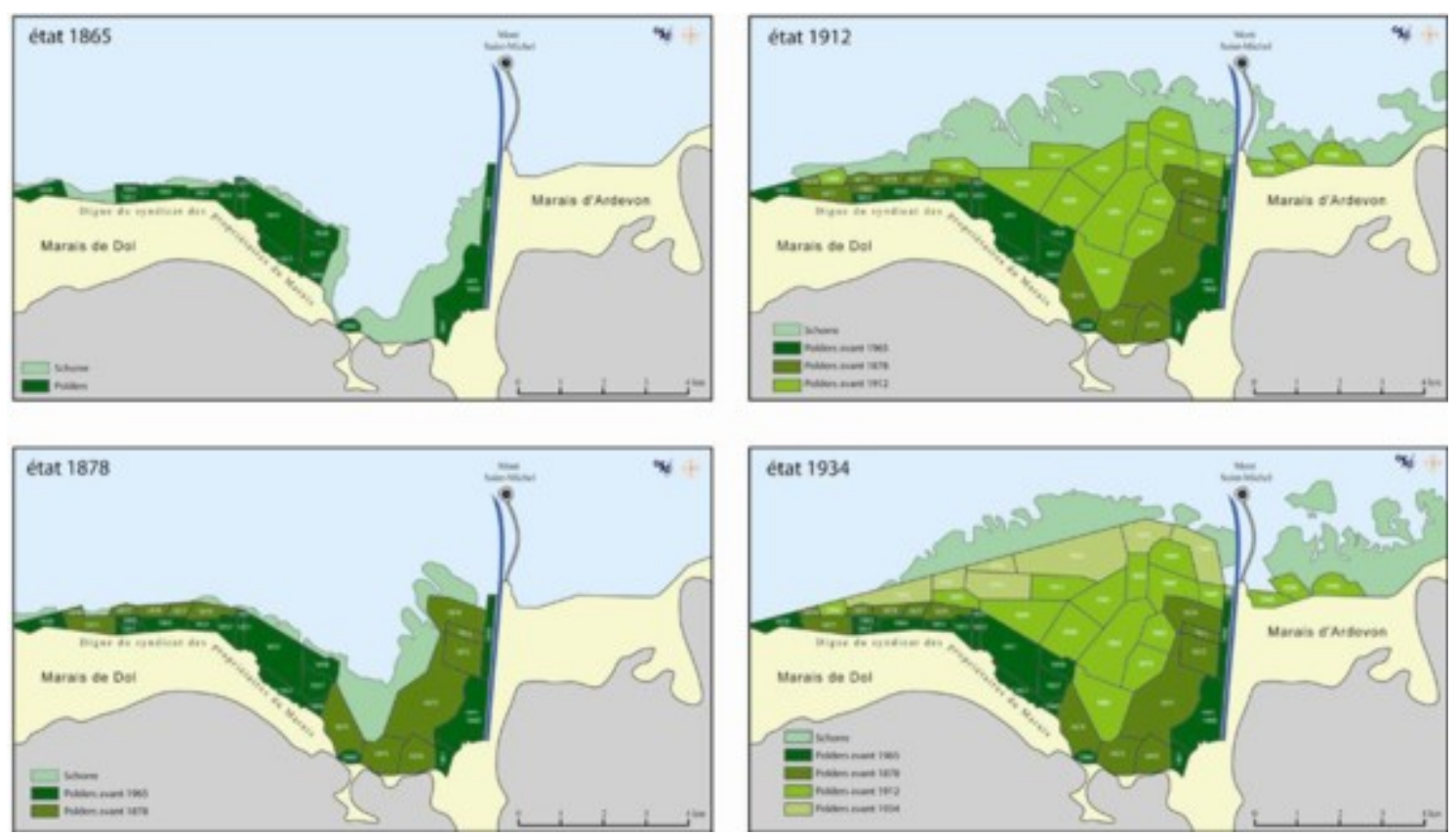

Figure 23. Les principales étapes de la poldérisation.

1969 : Construction du barrage de la Caserne sur le Couesnon

Ce barrage à portes à flot, construit pour empêcher la marée de remonter dans le lit fluvial du Couesnon, a réduit les volumes d'eau de mer pouvant pénétrer dans cet 


\section{XII ${ }^{\text {èmes }}$ Journées Nationales Génie Côtier - Génie Civil \\ Cherbourg, 12-14 juin 2012}

estuaire et favorisé le colmatage de son débouché sur l'estran au Sud du Mont. En effet, les cordons d'enrochements qui avaient été installés dès 1868 pour stabiliser le chenal entre le débouché du canal Mosselmann et le Mont sont recouverts par les sédiments estuariens du Couesnon dès 1972 (L'HOMER, 2002)

1970-1975 : Premières études en nature et en modèle réduit physique menées par le LCHF (MIGNIOT et VIGUIER, 2002) pour trouver des solutions afin de réduire la sédimentation aux abords du Mont et de stopper la progression des herbus. Des puissances hydrauliques suffisantes pour chasser les sédiments pouvaient être rétablies par l'aménagement du barrage de la Caserne, la création de réservoirs à marée à l'Est, la coupure partielle de la digue-route et enfin l'arasement de la digue de Roche Torin qui fût le seul chantier effectivement réalisé.

1983 : Arasement de la digue de Roche Torin pour permettre au chenal commun de la Sée et de la Sélune de divaguer vers le Sud et ainsi d'éroder une partie des schorres à l'Est du Mont. Une partie de cette digue a été conservée sur $500 \mathrm{~m}$ à la pointe de Roche Torin et une faible surface ( $10 \mathrm{ha})$ de ces herbus sera érodée par la divagation du chenal à l'extrémité de la digue actuelle. Cependant, le chenal étant ensuite reparti vers le Nord, les sédiments érodés se sont déposés sur le flanc Est du Grand Banc confortant la progression des schorres plus proches du Mont.

De très nombreuses études ont été menées à la fin des années 1990 pour trouver de nouvelles solutions permettant de rétablir des espaces balayés par la marée aux abords du Mont. Les nouveaux modèles numériques et physiques réalisés par SOGREAH (MIGNIOT \& VIGUIER, 2002) ont abouti à plusieurs aménagements successifs: élargissement du barrage de la Caserne et remplacement des portes à flot par des vannes, curage du lit du Couesnon et création d'un bassin de chasse dans l'anse de Moidrey, séparation du chenal du Couesnon en deux bras par un seuil de partage équipé d'épis déflecteurs, coupure de la digue route et remplacement par un pont passerelle à l'approche du Mont, déplacement des parkings situés au pied du Mont et création d'un parc de stationnement à terre entre Beauvoir et la Caserne.

2006 : Début des travaux sous la conduite du Syndicat Mixte pour le rétablissement du caractère maritime du Mont-Saint-Michel. Les premiers aménagements hydrauliques ont concerné l'aménagement de l'anse de Moidrey, le démantèlement de l'ancien barrage de la Caserne et la construction du nouveau barrage.

Mai 2009 : Mise en service du barrage de la Caserne. Les premiers résultats des lâchers d'eau montrent que le chenal principal du Couesnon orienté Nord-Ouest en 2009 a migré vers l'Est en contournant le pied du Mont (figure 24), provoquant par endroits de fortes érosions (jusqu'à $2 \mathrm{~m}$ ). De part et d'autre du Mont, la haute slikke située à une altitude supérieure à $5 \mathrm{~m}$ IGN a été réduite d'environ 30 ha. Au Sud-Ouest du Mont, les schorres apparus en 2003 ont disparu en 2011.

2010-2011 : Création du parc de stationnement à terre 
Mai 2012: Mise en service du parc de stationnement et des navettes pour accéder au Mont.

Mars 2012 : Début des travaux de construction (forage des pieux) du pont passerelle dont la finalisation est prévue en 2014.
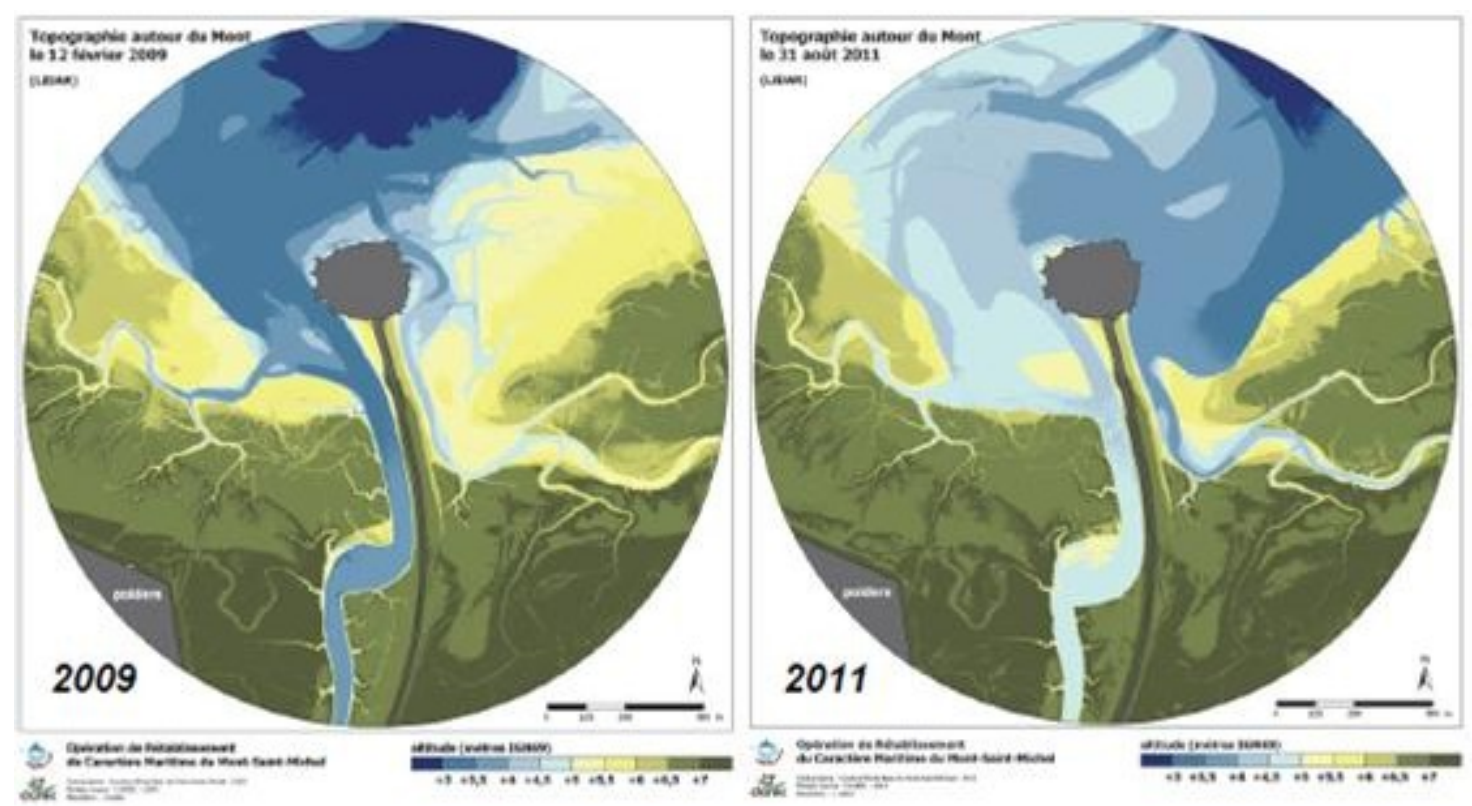

Figure 24. Evolution de la topographie aux abords du Mont entre 2009 et 2011, d'après R. DESGUEE, Syndicat Mixte baie du Mont-Saint-Michel (2012).

\section{Conclusion}

La configuration actuelle de la baie du Mont-Saint-Michel résulte d'une part de son évolution naturelle consécutive au remplissage sédimentaire holocène lié à la dernière phase de remontée du niveau marin et d'autre part des aménagements qui ont jalonné l'occupation humaine de cette frange littorale. Le processus de colmatage de la baie a permis de gagner de grandes surfaces de marais maritimes, qui ont ensuite été protégés des incursions marines et des divagations des chenaux par des digues délimitant le trait de côte. L'exceptionnelle largeur de l'estran a favorisé l'installation de pêcheries fixes dans la partie occidentale et de nombreuses salines ont été implantées principalement dans la zone estuarienne. La canalisation du Couesnon, les endiguements et la poldérisation, réalisés aux XIXème et XXème siècles, ont profondément modifié la ligne de rivage aux abords du Mont. La conchyliculture, développée au XXème siècle, occupe actuellement la majeure partie du bas estran occidental jusqu'à l'éventail des chenaux estuariens. La dynamique sédimentaire actuelle est dominée par les processus tidaux auxquels se surimpose une dynamique de houle qui remobilise les barrières littorales formées par les bancs coquilliers ou les flèches sableuses du littoral Nord-Est. 


\section{XII ${ }^{\text {èmes }}$ Journées Nationales Génie Côtier - Génie Civil \\ Cherbourg, 12-14 juin 2012}

Le bilan sédimentaire positif et la progression régulière des schorres montrent que le processus de colmatage naturel de la baie se poursuit. Les aménagements engagés pour le rétablissement du caractère maritime du Mont visent à redonner une puissance hydraulique suffisante et supérieure à la cohésion des sédiments, végétalisés ou non, pour réduire l'ensablement à proximité immédiate du Mont. La redistribution des sédiments érodés de part et d'autre du Mont favorisera l'extension latérale des herbus mais ne modifiera pas fondamentalement le budget sédimentaire à l'échelle de l'ensemble de la baie du Mont-Saint-Michel.

7. Références bibliographiques (Liste non exhaustive)

BILLARD, C., BERNARD, V., BOUFFIGNY, A., QUEVILLON, S. avec la coll. de ClAVEL, B., BILlEAUD, I., LAUTRIDOU, J.-P., L'HOMER, A., TESSIER, B. (2006). Archéologie des pêcheries dans la partie nord-orientale de la Baie du MontSaint-Michel. Compte-rendu de la journée "Civilisations atlantiques et Archéosciences", Rennes, 8 avril 2006. Rennes, UMR 6566 CNRS, pp 61-63.

BILLARD C., BERNARD V., BOUFFIGNY A., CLAVEL B., COUTURIER Y., JAOUEN G., LEDIGOL Y., QUEVILLON S., ROPARS A. (2012, à paraître). Techniques et modes d'exploitation des pêcheries sur le littoral normand (France) : un essai de bilan de 10 années de travaux archéologiques. In : Publication du colloque Homer Vannes 2011,

BILLEAUD I. (2006). Dynamique de construction d'un prisme sédimentaire littoral en régime mégatidal (la Baie du Mont-Saint-Michel). Thèse Université de Caen, 239 p.

BIZIEN-JAGLIN C. (2002). Les sites et gisements archéologiques du marais de Dol. In Bonnot-Courtois C., Caline B., L'Homer A. Le Vot M. (dir) La baie du Mont- SaintMichel et l'estuaire de la Rance. Environnements sédimentaires, aménagements et évolution récente. Bull. Cent. Rech. Elf-Explor. Prod., Mémoire 26, Total Fina ElfCNRS-EPHE, pp 164-176.

BIZIEN-JAGLIN C. (2008). Le sous-sol du marais. Un livre d'histoire ...humaine, sédimentaire et environnementale. In "De Sainte-Anne au Mont-Saint-Michel. Marais et polders de la baie". Communauté de communes Baie du Mont-Saint-Michel-Porte de Bretagne. Archives départementales d'Ille \& Vilaine (CG35), pp 15-20.

BONNOT-COURTOIS C., MAZE J.P., LE VOT M., AUGRIS C., EHRHOLD A., SIMPLET L., BLANCHARD M. (2009). Carte morpho-sédimentaire de la baie du Mont Saint-Michel (Ille-et-Vilaine et Manche) échelle 1/25 000, ed. Quae - Ifremer BONNOT-COURTOIS C., BASSOULlET P., TESSIER B., CAYOCCA F., LE HIR P., BALTZER A. (2008). Remaniements sédimentaires superficiels sur l'estran occidental de la baie du Mont-Saint-Michel. European Journal of Environmental and Civil Engineering, 978-2-7462-1971-7, vol. 12, n¹-2, pp 51-65. doi:10.3166/ejece.12.5165 
BONNOT-COURTOIS C., CALINE B., L'HOMER A., LE VOT M. (éd) (2002). La baie du Mont-Saint-Michel et l'estuaire de la Rance. Environnements sédimentaires, aménagements et évolution récente. [The bay of Mont-Saint-Michel and the Rance estuary. Recent development and evolution of depositional environments]. Bull. Cent. Rech. Elf-Explor. Prod., Mémoire 26, Total Fina Elf-CNRS-EPHE, 256 p.

BONNOT-COURTOIS C., LEVASSEUR J.-E. (2000). Etudes en Environnement. Volume 5 . Contribution à la connaissance de la dynamique des herbus. Rapport final Syndicat Mixte pour le Rétablissement du caractère maritime du Mont-Saint-Michel. Mission Mont-Saint-Michel DDE Manche. Univ. Rennes 1, UMR 8586 Prodig CNRS. $196 \mathrm{p}$.

BONNOT-COURTOIS C., LEVASSEUR J.E. (2012). Organisation générale de la végétation littorale des estrans vaseux. In Manuel d'étude et de gestion des oiseaux et de leurs habitats en zone côtière. Chap. 1, Ecosystèmes estuariens et littoraux. pp 23-60. AESTUARIA [URL http://dl.dropbox.com/u/42831955/gestion\%20littorale.pdf]

DESGUEE R. (2012). Cahier technique. Suivi de l'efficacité du Barrage. Syndicat Mixte Baie du Mont Saint Michel. La Baie. n²9, pp 6-7.

EHRHOLD A. (1999). Dynamique de comblement d'un bassin sédimentaire soumis à un régime mégatidal : exemple de la baie du Mont-Saint-Michel. Thèse, Université de Caen, 294 p. + annexes.

JORET E. (2008). Grèves vertes et grèves blanches. in "De Sainte-Anne au Mont-SaintMichel. Marais et polders de la baie". Communauté de communes Baie du Mont-SaintMichel-Porte de Bretagne. Archives départementales d'Ille \& Vilaine (CG35), pp 2739.

LARSONNEUR C. \& coll. (1989). La baie du Mont-Saint-Michel : un modèle de sédimentation en zone tempérée. Bull. Inst. Géol. Bassin Aquitaine, 46, pp 1-75.

LEFEUVRE J.-C. (ed) \& coll. (1996). Effects of environmental change on european salt-marshes. Rapport final vol 2, Laboratoire d'Evolution des Systèmes Naturels et Modifiés. Univ. Rennes 1, MNHN, 251 p.

LEFEUVRE J.-C., MOUTON J.-P., MAUXION A. (2009). L'histoire de la baie du Mont-Saint-Michel et de son abbaye. Editions Ouest-France. 287 p.

L'HOMER A., COURBOULEIX S., CHANTRAINE J., DEROIN J.P. (1999) avec la collaboration de BONNOT-COURTOIS C., CALINE B., EHRHOLD A., LAUTRIDOU J.-P., MORZADEC-KERFOURN M.T. (1999). Carte géologique de France (1/50 000), feuille Baie du Mont-Saint-Michel, (208), Orléans, BRGM. Notice explicative. $183 \mathrm{p}$.

L'HOMER A. (1995). Les vestiges de la pêcherie en bois de Saint-Jean-le-Thomas datent de l'âge du Bronze. In "Baie du Mont-Saint-Michel et Marais de Dol", L. Langouet \& M.-T. Morzadec-Kerfourn (dir.), Saint-Malo, Centre régional d'archéologie d'Alet. pp 119-124. 


\section{XII ${ }^{\text {èmes }}$ Journées Nationales Génie Côtier - Génie Civil \\ Cherbourg, 12-14 juin 2012}

L'HOMER A. (2002). Impact sédimentologique des aménagements sur l'estuaire du Couesnon. In Bonnot-Courtois C., Caline B., L'Homer A. Le Vot M. (dir) La baie du Mont- Saint-Michel et l'estuaire de la Rance. Environnements sédimentaires, aménagements et évolution récente. Bull. Cent. Rech. Elf-Explor. Prod., Mémoire 26, Total Fina Elf-CNRS-EPHE, pp 153-163.

L'HOMER A., PIQUOIS C. (2002). Baie du Mont-Saint-Michel. Les anciennes salines. Siloë ed. $175 \mathrm{p}$.

L'HOMER A., BONNOT-COURTOIS C., CALINE B. (2002). Le prisme sédimentaire des dépôts du marais de Dol : essai de reconstitution de la mise en place des dépôts. In Bonnot-Courtois C., Caline B., L'homer A., Le Vot M. (dir), La baie du Mont-SaintMichel et l'estuaire de la Rance. Environnements sédimentaires, aménagements et évolution récente. Bull. Cent. Rech. Elf-Explor. Prod., Mémoire 26, Total Fina ElfCNRS-EPHE, pp 177-196

L'HOMER A. (2008). Passé géologique et naissance de la baie. In "De Sainte Anne au Mont-Saint-Michel. Marais et polders de la baie." Communauté de communes Baie du Mont-Saint-Michel-Porte de Bretagne. Archives départementales d'Ille \& Vilaine (CG35). pp 11-14.

MIGNIOT C. (1998). Rétablissement du caractère maritime du Mont-Saint-Michel. Synthèse des connaissances hydro-sédimentaires de la baie. Rapport DDE Manche, Mission Mont-Saint-Michel, $111 \mathrm{p}$.

MORZADEC-KERFOURN M.-T. (2002). La sédimentation holocène dans la partie occidentale de la baie du Mont-Saint-Michel: l'évolution du marais de Dol de Bretagne. In Bonnot-Courtois C., Caline B., L'Homer A. Le Vot M. (dir) La baie du Mont-Saint-Michel et l'estuaire de la Rance. Environnements sédimentaires, aménagements et évolution récente. Bull. Cent. Rech. Elf-Explor. Prod., Mémoire 26, Total Fina Elf-CNRS-EPHE, pp 153-163.

NIKODIC J. (1981). Dynamique sédimentaire dans la partie occidentale de la baie du Mont-Saint-Michel. Thèse 3ème cycle, Université de Nantes, $180 \mathrm{p}$.

SACHET C. (2008). Digues et contre-digues. in "De Sainte-Anne au Mont-SaintMichel. Marais et polders de la baie". Communauté de communes Baie du Mont-SaintMichel-Porte de Bretagne. Archives départementales d'Ille \& Vilaine (CG35). pp 41-60.

SORNIN J.-M. (1981). Processus sédimentaires et biodéposition liés à différents modes de conchyliculture. Thèse 3ème cycle, Université de Nantes, $185 \mathrm{p}$.

TESSIER B., BILLEAUD I., LESUEUR P. (2006) - The Bay of Mont-Saint-Michel northeastern littoral: an illustrative case of coastal sedimentary body evolution and stratigraphic organization in a transgressive/highstand context. Bull. Soc. Geol. Fr., t. 177, n², pp 71-78. 
Thème 2 - Dynamique sédimentaire

TESSIER B., BILLEAUD I., BONNOT-COURTOIS C., CALINE B. (2007). La baie du Mont-Saint-Michel. Faciès, séquence, évolution. 11ème Congrès français de sédimentologie, Caen 2007, Livret d'excursion, Publ. ASF, n 58, 48 p.

WEILL P., TESSIER B., MOUAZÉ D., BONNOT-COURTOIS C., NORGEOT C. (2010). Shelly cheniers on a macrotidal flat (Mont-Saint-Michel bay, France) - Internal architecture revealed by ground-penetrating radar. Journal of Sedimentary Geology, Vol. 17 december 2010. doi:10.1016/j.sedgeo.2010.12.002

WEILL P. (2010). Formation et évolution de cheniers en contexte macrotidal. Approches expérimentales et in situ. Thèse Université de Caen, $230 \mathrm{p}+$ Annexes. 